\title{
On the Economic Sources of Stock Market Volatility*
}

\author{
Robert F. Engle Eric Ghysels $^{\ddagger} \quad$ Bumjean Sohn $^{\S}$
}

First Draft: October 2005

This Draft: August 31, 2008

\begin{abstract}
We revisit the relation between stock market volatility and macroeconomic activity using a new class of component models that distinguish short run from secular movements. We combine insights from Engle and Rangel (2007) and the recent work on mixed data sampling (MIDAS), as in e.g. Ghysels, Santa-Clara, and Valkanov (2005). The new class of models is called GARCH-MIDAS, since it uses a mean reverting unit daily GARCH process, similar to Engle and Rangel (2007), and a MIDAS polynomial which applies to monthly, quarterly, or bi-annual macroeconomic or financial variables. We study long historical data series of aggregate stock market volatility, starting in the 19th century, as in Schwert (1989). We formulate models with the long term component driven by inflation and industrial production growth that are at par in terms of out-of-sample prediction for horizons of one quarter and out-perform more traditional time series volatility models at longer horizons. Hence, imputing economic fundamentals into volatility models pays off in terms of long horizon forecasting. We also find that at a daily level, inflation and industrial production growth, account for between $10 \%$ and $35 \%$ of oneday ahead volatility prediction. Hence, macroeconomic fundamentals play a significant role even at short horizons. Unfortunately, all the models - purely time series ones as well as those driven by economic variables - feature structural breaks over the entire sample spanning roughly a century and a half of daily data. Consequently, our analysis also focuses on subsamples pre-WWI, the Great Depression era, and post-WWII (also split to examine the so called Great Moderation). Our main findings remain valid across subsamples.
\end{abstract}

${ }^{*}$ We are most grateful to Bill Schwert for providing us with data used in his 1989 paper and Gonzalo Rangel for help with the Spline-GARCH estimations. We thank Chris Carroll, Frank Diebold, Xavier Gabaix, Chris Jones, Andrew Karolyi, Oliver Linton, Stijn Van Nieuwerburgh, Robert Whitelaw and seminar participants at the 2008 American Finance Association Meetings, the 2007 North American Meetings of the Econometric Society, Johns Hopkins University, London School of Economics, New York University, Ohio State University, Oxford University, University of North Carolina and University of Pittsburgh for helpful comments.

${ }^{\dagger}$ Department of Finance, Stern School of Business, New York University, e-mail: rengle@stern.nyu.edu

${ }^{\ddagger}$ Department of Finance, Kenan-Flagler Business School, and Department of Economics, University of North Carolina at Chapel Hill, email: eghysels@unc.edu

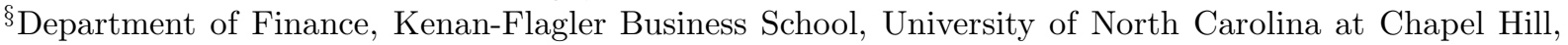
e-mail: sohnb@kenan-flagler.unc.edu 


\section{Introduction}

We have made substantial progress on modelling the time variation of volatility. Unfortunately, progress has been uneven. We have a better understanding of forecasting volatility over relatively short horizons, ranging from one day ahead to several weeks. A key ingredient is volatility clustering, a feature and its wide-range implications, first explored in the seminal paper on ARCH models by Engle (1982). We also bridged the gap between discrete time models, such as the class of ARCH models, and continuous time models, such as the class of Stochastic Volatility (SV) models with close links to the option pricing literature 1 As a by-product we moved ahead on linking discrete time volatility prediction and option pricing. As a matter of fact, we are now much more comfortable with the notions of objective and risk neutral probability measures and know how to empirically implement them compared to, say fifteen years ago 2

Despite the impressive list of areas where we made measurable and lasting progress, we are still struggling with some basic issues. For example, Schwert (1989) wrote a paper with the pointed title, Why Does Stock Market Volatility Change Over Time? Schwert tried to address the relation between stock volatility and (1) real and nominal macroeconomic volatility, (2) the level of economic activity, as well as (3) financial leverage 3 Roughly around the same time Fama and French (1989) and Ferson and Harvey (1991), documented the empirical regularity that risk-premia are counter cyclical. This finding prompted research on asset pricing models which provide rational explanations for counter cyclical stock market volatility and risk premia 4

\footnotetext{
${ }^{1}$ For surveys of the ARCH literature, see e.g. Bollerslev, Engle, and Nelson (1994). For a survey of SV models see e.g. Ghysels, Harvey, and Renault (1996) and Shephard (2005).

${ }^{2}$ On the topic of discrete time ARCH and continuous time diffusions, see e.g. Nelson (1990), Foster and Nelson (1996) and Drost and Werker (1996), among others. The subject of option pricing and volatility prediction is covered in many papers, two survey papers are worth mentioning, namely Bates (1996) and Garcia, Ghysels, and Renault (2003).

${ }^{3}$ Before Schwert, Officer (1972) related changes to volatility to macroeconomic variables, whereas many authors have documented that macroeconomic volatility is related to interest rates.

${ }^{4}$ Examples include the time-varying risk aversion model of Campbell and Cochrane (1999) with external habit formation, the prospect theory approach of Barberis, Huang, and Santos (2001) generates similar counter cyclical variations in risk-premia. Counter cyclical stock market volatility also relates to the socalled feedback effect - the effect by which asset returns and volatility are negatively correlated (see e.g. Campbell and Hentschel (1992) among others). Along different lines, Bansal and Yaron (2004) and Tauchen (2005) argue that investors with a preference for early resolution of uncertainty require compensation, thereby inducing negative co-movements between ex-post returns and volatility. Some of the models on limited stock market participation such as Basak and Cuoco (1998) are also able to generate asymmetric stock market volatility movements. These theories are important for they highlight the main mechanisms linking stock
} 
In this paper we revisit modelling the economic sources of volatility. The progress of the last fifteen years allows us to approach this question with various new insights, matured during the last two decades of research on volatility. We start from the observation that volatility is not just volatility, as we have come to understand that there are different components to volatility and that there are gains to modelling these components separately. It is this insight that enables us also to shed new light on the link between stock market volatility and economic activity. In recent years, various authors have advocated the use of component models for volatility. Engle and Lee (1999) introduced a GARCH model with a long and short run component. Several others have proposed related two-factor volatility models, see e.g. Ding and Granger (1996), Gallant, Hsu, and Tauchen (1999), Alizadeh, Brandt, and Diebold (2002), Chernov, Gallant, Ghysels, and Tauchen (2003) and Adrian and Rosenberg (2004) among many others. The latter examine quite an exhaustive set of diffusion models for the stock price dynamics and conclude quite convincingly that at least two components are necessary to adequately capture the dynamics of volatility. While the principle of multiple components is widely accepted, there is no clear consensus how to specify the dynamics of each of the components. The purpose of this paper is to suggest several new component model specifications with direct links to economic activity.

Practically speaking, the research pursued in this paper is inspired by two recent contributions. The first is Engle and Rangel (2007) who introduce a Spline-GARCH model where the daily equity volatility is a product of a slowly varying deterministic component and a mean reverting unit GARCH. Unlike conventional GARCH or stochastic volatility models, this model permits "unconditional" volatility to change over time. Engle and Rangel (2007) use an exponential spline as a convenient non-negative parameterization. A second goal of their paper is also to explain why this "unconditional" volatility changes over time and differs across financial markets. The model is applied to equity markets for 50 countries for up to 50 years of daily data and the macroeconomic determinants of volatility are investigated. Engle and Rangel (2007) find that volatility in macroeconomic factors such as GDP growth, inflation and short term interest rate are important explanatory variables that increase volatility. There is evidence that high inflation and slow growth of output are also positive determinants. This analysis draws upon the cross-sectional behavior of the spline component across 50 countries.

In the present paper we focus instead on long historical time series, similar to Schwert (1989).

market volatility to macroeconomic factors. 
While the spline specification could still be used, we explore a very different approach that allows us to better handle the links between stock market data, observed on a daily basis, and macroeconomic variables that are sampled monthly or quarterly. For example, in Schwert (1989), daily data are aggregated to monthly realized volatilities, which are then used to examine the link between stock market volatility and economic activity. If there are several components to volatility, monthly realized volatility may not be a good measure to consider. Rather, we would like to use the long term component. To do so, we adopt a framework that is suited to combine data that are sampled at different frequencies. The new approach is inspired by the recent work on mixed data sampling, or MIDAS. In the context of volatility, Ghysels, Santa-Clara, and Valkanov (2005) studied the traditional risk-return trade-off and used monthly data to proxy expected returns while the variance was estimated using daily squared returns.

We use the MIDAS approach to link macroeconomic variables to the long term component. Hence, the new class of models is called GARCH-MIDAS, since it uses a mean reverting unit daily GARCH process, similar to Engle and Rangel (2007), and a MIDAS polynomial which applies to monthly, quarterly, or bi-annual macroeconomic or financial variables. Having introduced the GARCH-MIDAS model that allows us to extract two components of volatility, one pertaining to short term fluctuations, the other pertaining to a secular component, we are ready to revisit the relationship between stock market volatility and economic activity and volatility. The first specification we consider uses exclusively financial series. The GARCH component is based on daily (squared) returns, whereas the long term component is based on realized volatilities computed over a monthly, quarterly or bi-annual basis. In some sense, the original work of Schwert comes closest to this specification, as the long term component is a filtered realized volatility process, whereas Schwert uses raw realized volatilities (on a monthly basis). The GARCH-MIDAS model with a long run component based on realized volatility will be a benchmark model, against which we can measure success of empirical specifications involving macroeconomic variables. The GARCH-MIDAS model with a long run component based on realized volatility will also be compared to existing component models - including the Spline-GARCH.

The GARCH-MIDAS model also allows us to examine directly the macro-volatility links, avoiding the two-step procedure used by Schwert. Indeed, we can estimate GARCH-MIDAS models where macroeconomic variables enter directly the specification of the long term component. The fact that the macroeconomic series are sampled at a different frequency is 
not an obstacle, again due to the advantages of the MIDAS scheme. Hence, compared to the original work of Schwert, our approach has the following advantages: (1) we separate short and long run components of volatility, (2) we use either a filtered realized variances or a direct approach imputing macroeconomic time series to capture the economic sources of stock market volatility. We focus on two key economic variables: (1) inflation and (2) industrial production growth.

The main findings of the paper can be summarized as follows. In terms of forecasting, we find that the new class of models driven by economic variables are roughly at par with time series volatility models at the quarterly horizon and outperform them at the semi-annual horizon. Hence, imputing economic fundamentals - inflation and industrial production growth - into volatility models pays off in terms of long horizon forecasting. We also find that at a daily level, industrial production and inflation account for between $10 \%$ and $35 \%$ of expected one-day ahead volatility. Unfortunately, all the models - purely time series ones as well as those driven by economic variables - feature structural breaks over the entire sample spanning roughly a century and a half of daily data. This is not entirely unexpected as the long span of data covers fundamental changes in the economy - although the Spline-GARCH and GARCH-MIDAS models are designed to capture fundamental shifts. Our results suggest they do not fully capture this. Consequently, our analysis also focuses on subsamples - preWWI, the Great Depression era, and post-WWII (also split to examine the so called Great Moderation). Our findings are robust across subsamples - except the pre-WWI one. The latter is presumably plagued by poor measurement of inflation and industrial production. Hence, macroeconomic fundamentals play a significant role even at short horizons.

A first section 2 describes the new class of component models for stock market volatility, followed by section 3 and section 4 which cover the empirical implementation of the new class and revisits the relationship between stock market volatility and macro variables. Conclusions appear in section 5 .

\section{A New Class of Component Models for Stock Market Volatility}

Different news events may have different impacts on financial markets, depending on whether they have consequences over short or long horizons. A conventional framework to analyze 
this is the familiar log linearization of Campbell (1991) and Campbell and Shiller (1988) which states that:

$$
r_{i, t}-E_{i-1, t}\left(r_{i, t}\right)=\left(E_{i, t}-E_{i-1, t}\right) \sum_{j=0}^{\infty} \rho^{j} \Delta d_{i t+j}-\left(E_{i, t}-E_{i-1, t}\right) \sum_{j=1}^{\infty} \rho^{j} r_{i t+j}
$$

where we deliberately write returns in terms of days of the month, namely $r_{i, t}$ is the log return on day $i$ during month $t, d_{i, t}$ the log dividend on that same day and $E_{i, t}()$ the conditional expectation given information at the same time. Following Engle and Rangel (2007), the left hand side of equation (11), or unexpected returns, can be rewritten as follows:

$$
r_{i, t}-E_{i-1, t}\left(r_{i, t}\right)=\sqrt{\tau_{t} \cdot g_{i, t}} \varepsilon_{i, t}
$$

where volatility has at least two components, namely $g_{i, t}$ which accounts for daily fluctuations that are assumed short-lived, and a secular component $\tau_{t} 5$ The main idea of equation (2), is that the same news, say better than expected dividends, may have a different effect depending on the state of the economy. For example, unexpected poor earnings, should have an impact during expansion different from that during recessions. The component $g_{i, t}$ is assumed to relate to the day-to-day liquidity concerns and possibly other short-lived factors (see e.g. recent work by Chordia, Roll, and Subrahmanyam (2002) documents quite extensively the impact of liquidity on market fluctuations). In contrast, the component $\tau_{t}$ relates, first and foremost, to the future expected cash flows and future discount rates, and macro economic variables are assumed to tell us something about this source of stock market volatility.

Various component models for volatility have been considered, see e.g. Engle and Lee (1999), Ding and Granger (1996), Gallant, Hsu, and Tauchen (1999), Alizadeh, Brandt, and Diebold (2002), Chernov, Gallant, Ghysels, and Tauchen (2003) and Adrian and Rosenberg (2004), among many others. The contributions of our work pertain to modelling $\tau_{t}$ and are inspired by the recent work on mixed data sampling, or MIDAS, discussed in a context similar to the one used here - namely volatility filtering - by Ghysels, Santa-Clara, and Valkanov (2005). Generically, we will call the new class of models GARCH-MIDAS component models. The distinct feature of the new class is that the mixed data sampling allows us to link volatility directly to economic activity (i.e. data that is typically sampled at the different frequency

\footnotetext{
${ }^{5}$ Note that the specification in equation (2) is slightly different from that in Engle and Rangel (2007) in that the $\tau$ component in equation (2) is assumed constant throughout the month, quarter or half-year, an assumption made here for convenience. Later, we will also introduce a specification where this restriction is removed and the $\tau$ component varies daily.
} 
than daily returns). Practically speaking, there will be two cases which will be studied in this paper. They are: (1) the component $\tau_{t}$ does not change for a fixed time span and involves low frequency financial or macroeconomic data, and (2) the component $\tau_{t}$ changes daily and involves rolling windows of financial data.

The easiest case is the fixed window case, and it is therefore the first we will cover in subsection 2.1. We also cover the rolling window specification in the same subsection. Next, in subsection 2.2 we cover alternative specifications involving macro variables directly.

\subsection{Models with Realized Volatility}

We start again with equation (2) but consider the return for day $i$ of any arbitrary period $t$ - which may be a month, quarter, etc., and has $N_{t}$ days - which may vary with $t$. Since the time scale is not important for the exposition of the model we will treat $t$ as a month, so that $r_{i, t}$ is day $i$ of month $t$. It will matter empirically which frequency to select and one of the advantages of our approach is that $t$ will be a choice variable that will be selected as part of the model specification. For the moment we do not discuss this yet, and therefore let $t$ be fixed at the monthly frequency, but the reader can keep in mind that $t$ is a fixed window which will be determined via empirical model selection criteria. The return on day $i$ in month $t$ is written as (assuming for notational convenience it is not the first day of the period):

$$
r_{i, t}=\mu+\sqrt{\tau_{t} \cdot g_{i, t}} \varepsilon_{i, t}, \quad \forall i=1, \ldots, N_{t}
$$

where $\varepsilon_{i, t} \mid \Phi_{i-1, t} \sim N(0,1)$ with $\Phi_{i-1, t}$ is the information set up to day $(i-1)$ of period $t$. Following Engle and Rangel (2007), we assume the volatility dynamics of the component $g_{i, t}$ is a (daily) $\operatorname{GARCH}(1,1)$ process, namely:

$$
g_{i, t}=(1-\alpha-\beta)+\alpha \frac{\left(r_{i-1, t}-\mu\right)^{2}}{\tau_{t}}+\beta g_{i-1, t}
$$

The first specification of the $\tau$ component for GARCH-MIDAS builds on a long tradition going back to Merton (1980), Schwert (1989) and others, of measuring long run volatility by realized volatility over a monthly or quarterly horizon. In particular, consider monthly realized volatility, denoted $R V_{t}$. Unlike the previous work, however, we do not view the realized volatility of a single quarter or month as the measure of interest. Instead, we specify 
the $\tau_{t}$ component by smoothing realized volatility in the spirit of MIDAS regression and MIDAS filtering:

$$
\begin{aligned}
\tau_{t} & =m+\theta \sum_{k=1}^{K} \varphi_{k}\left(\omega_{1}, \omega_{2}\right) R V_{t-k} \\
R V_{t} & =\sum_{i=1}^{N_{t}} r_{i, t}^{2}
\end{aligned}
$$

Note also that the $\tau$ component is predetermined, namely:

$$
E_{t-1}\left[\left(r_{i, t}-\mu\right)^{2}\right]=\tau_{t} E_{t-1}\left(g_{i, t}\right)=\tau_{t}
$$

assuming the beginning of period expectation of the short term component, $E_{t-1}\left(g_{i, t}\right)$, to be equal to its unconditional expectation, namely $E_{t-1}\left(g_{i, t}\right)=1$. To complete the model we need to specify the weighting scheme for equation ([6), namely:

$$
\varphi_{k}(\omega)= \begin{cases}\frac{(k / K)^{\omega_{1}-1}(1-k / K)^{\omega_{2}-1}}{\sum_{j=1}^{K}(j / K)^{\omega_{1}-1}(1-j / K)^{\omega_{2}-1}} & \text { Beta } \\ \omega^{k} /\left(\sum_{j=1}^{K} \omega^{j}\right) & \text { Exp. Weighted }\end{cases}
$$

where the weights in the above equation sum up to one. The weighting function or smoothing function in equation (8) is either the "Beta" lag structure discussed further in Ghysels, Sinko, and Valkanov (2006) or the commonly used "Exponentially weighting". The Beta lag, based on the beta function, is very flexible to accommodate various lag structures. It can represent monotonically increasing or decreasing weighting scheme. It can also represent a humpshaped weighting scheme although it is limited to unimodal shapes. 6

Equations (33)-(6) and (8) form a GARCH-MIDAS model for time-varying conditional variance with fixed time span RV's and parameter space $\Theta=\left\{\mu, \alpha, \beta, m, \theta, \omega_{1}, \omega_{2}\right\}$. This first model has a few nice features. First, the number of parameters are fixed and it is parsimonious relative to the existing component volatility models which typically are not parsimonious. Second, since the number of parameters are fixed, we can compare various GARCH-MIDAS models with different time spans. Indeed, as noted before $t$ can be a

\footnotetext{
${ }^{6}$ See Ghysels, Sinko, and Valkanov (2006) for further details regarding the various patterns one can obtain with Beta lags.
} 
month, quarter or semester. Therefore, we can vary $t$ and profile the log likelihood function to maximize with respect to the time span covered by $R V$. Moreover, the number of lags in MIDAS can vary as well, again while keeping the parameter space fixed. This is a nice feature that will be exploited at the stage of empirical model selection. Note that we can take, say a monthly $R V$, and take 12 lags, or a quarterly $R V$ with 4 lags. Both involve the same daily squared returns, yet the application of the weighting scheme in equation (86) implies different weights across the year.

Another interpretation of our approach is to view the GARCH-MIDAS model as a filter. We know from recent work by Barndorff-Nielsen and Shephard (2002) and Jacod (1994) that the monthly realized volatilities are a very noisy measure of volatility. One answer to improve precision is to use high frequency data. However, we only have on record roughly 15 years of such data. For longer data spans we need to rely on filtering, and in this respect we can view equation (5) as a filter of $R V_{t}$. The estimation procedure, to be discussed later, will allow us to obtain appropriate weights for the volatility filter.

Next we consider a rolling window specification for the MIDAS filter. Namely, we remove the restriction that $\tau_{t}$ is fixed for month $t$, which makes $\tau$ and $g$ both change at the daily frequency. We will do this by introducing the 'rolling window RV' as opposed to the 'fixed span RV' specification. A GARCH-MIDAS model with rolling window RV can be defined as follows:

$$
R V_{i}^{(r w)}=\sum_{j=1}^{N^{\prime}} r_{i-j,}^{2}
$$

where we use the notation $r_{i-j}$,. to indicate that we roll back the days across various periods $t$ without keep track of it. When $N^{\prime}=22$, we call it monthly rolling window RV, while $N^{\prime}=65$ and $N^{\prime}=125$, amount to respectively, quarterly rolling and biannual rolling window RV. Furthermore, the $\tau$ process can be redefined accordingly,

$$
\tau_{i}^{(r w)}=m^{(r w)}+\theta^{(r w)} \sum_{k=1}^{K} \varphi_{k}\left(\omega_{1}, \omega_{2}\right) R V_{i-k}^{(r w)}
$$

Finally, we drop ' $t$ ' from equations (3) and (44) (since everything is of daily frequency now) and, together with equations (8)-(10), they form the class of GARCH-MIDAS models with rolling window RV. Note that, it still maintains all the nice features from GARCH-MIDAS with fixed span RV that were previously mentioned. 
To conclude we will also consider a log version of the GARCH-MIDAS, namely for the fixed time span case we replace equation (5) by:

$$
\log \tau_{t}=m+\theta \sum_{k=1}^{K} \varphi_{k}\left(\omega_{1}, \omega_{2}\right) R V_{t-k}
$$

and its rolling sample counterpart is defined similarly. We consider a log version as it matches the class of models involving macroeconomic variables introduced next.

\subsection{Incorporating Macroeconomic Information Directly}

We now turn to volatility models that directly incorporate macroeconomic time series. The class of GARCH-MIDAS models, so far involving realized volatility, allows us to do this. The GARCH-MIDAS models discussed so far, were based on one-sided MIDAS filters, and therefore yielding prediction models. In this section we present GARCH-MIDAS models with one-sided filters, involving past macroeconomic variables. Also, for comparison, at the end of the section we introduce two-sided filters involving macroeconomic variables.

We will consider various specifications going from specific to general. Moreover, we consider fixed span specifications and take a quarterly frequency:

$$
\log \tau_{t}=m_{l}+\theta_{l} \sum_{k=1}^{K_{l}} \varphi_{k}\left(\omega_{1, l}, \omega_{2, l}\right) X_{l, t-k}^{m v}
$$

where $X_{l, t-k}^{m v}$ is the level (hence the subscripts $l$ ) and of a macro variable ' $m v^{\prime}$. The macroeconomic variables of interest are industrial production growth rate (IP), and producer price index inflation rate (PPI). As explained later, when we provide the details of the data configurations, by level we mean inflation and IP growth. Hence, we are dealing with two models with a single series explaining the long run component.

Both series also feature volatility, i.e. inflation and IP growth volatility, which will be measured similar to Schwert (1989), using innovations from autoregressive models. This yields the next two GARCH-MIDAS models featuring macroeconomic volatility:

$$
\log \tau_{t}=m_{v}+\theta_{v} \sum_{k=1}^{K_{v}} \varphi_{k}\left(\omega_{1, v}, \omega_{2, v}\right) X_{v, t-k}^{m v}
$$


where $X_{v, t-k}^{m v}$ represents the volatility which will be characterized later. Note that we use different weighting schemes for levels and volatility - hence the superscripts $l$ and $v$ to the weighting scheme parameters.

We also consider a model which combines the level and volatility of each series, namely:

$$
\begin{aligned}
\log \tau_{t}= & m_{l v}+\theta_{l} \sum_{k=1}^{K_{l}} \varphi_{k}\left(\omega_{1, l}, \omega_{2, l}\right) X_{l, t+k}^{m v} \\
& +\theta_{v} \sum_{k=1}^{K_{v}} \varphi_{k}\left(\omega_{1, v}, \omega_{2, v}\right) X_{v, t+k}^{m v}
\end{aligned}
$$

Hence, we have now two models, one for IP growth and one for PPI, representing the long run impact on stock market volatility of their level and volatility. We also estimated a general model specification that combines all four series. Such a model involves a lot more parameters, since the weighting schemes for both volatility and the level of IP and PPI differ and therefore double the parameter space. More specifically, the $\tau$ component in this case involves 13 parameters compared to the single variable models in equation (12) which involve 4 parameters (in both cases not counting the GARCH parameters). The results are available upon request but not reported here.

In a sense one can think of equations (12) through (14) in the context of regression models with a latent regressand, which we are able to estimate through the maximization of the likelihood function. In particular, if we denote in equation (3) the conditional variance $\sigma_{i t}^{2}$ $=\tau_{t} \cdot g_{i, t}$, then we can write in the general case (combining all the series):

$$
\begin{aligned}
\log \sigma_{i t}^{2}= & m_{l v 2}+\sum_{m v=I P, P P I} \theta_{l, m v} \sum_{k=1}^{K_{l}^{m v}} \varphi_{k}\left(\omega_{1, m v, l}, \omega_{2, m v, l}\right) X_{l, t+k}^{m v} \\
& +\sum_{m v=I P, P P I} \theta_{v, m v} \sum_{k=1}^{K_{v}^{m v}} \varphi_{k}\left(\omega_{1, m v, v}, \omega_{2, m v, v}\right) X_{v, t+k}^{m v}+\log g_{i t}
\end{aligned}
$$

where the "residual" is $\log g_{i t}$, i.e. the $\operatorname{GARCH}(1,1)$ component. The comparison with regression models is not entirely accurate, however, since we do not impose orthogonality of the regressors with the residuals, i.e. the orthogonality between $g$ and $\tau$. Nevertheless, it is useful to think of these models as having explanatory variables.

To conclude we present GARCH-MIDAS models with two-sided filters - where the latter 
involve both past and future macroeconomic variables. This provides us with a tool to assess how much market volatility dynamics relate to both past and future macroeconomic activity. The specification we consider (taking again a quarterly frequency and a fixed span) for a single series - levels and volatility - is:

$$
\begin{aligned}
\log \tau_{t}= & m_{2}+\sum_{k=-K_{l}^{(l)}}^{K_{f}^{(l)}} \varphi_{k}\left(\omega_{1}, \omega_{2}\right) \theta_{l}^{(k)} X_{l, t+k}^{m v} \\
& +\sum_{k=-K_{l}^{(v)}}^{K_{f}^{(v)}} \varphi_{k}\left(\omega_{3}, \omega_{4}\right) \theta_{v}^{(k)} X_{v, t+k}^{m v}
\end{aligned}
$$

where we allow for different slope coefficients for leads and lags, namely:

$$
\theta_{l / v}^{(k)}= \begin{cases}\theta_{l / v}^{f} & \forall k, k \geq 0 \\ \theta_{l / v}^{b} & \forall k, k<0\end{cases}
$$

hence the impact on volatility of past as opposed to expected future realizations of macroeconomic variables is allowed to differ 7

It should also be noted that the two-sided model specification in (15) is in the spirit of causality tests proposed by Sims (1972). Being able to examine potential causal forwardlooking behavior of volatility is particularly important since stock market volatility - being counter cyclical - tends to lead economic activity 8

In the remainder of the paper we will not use the two-sided filters for the evaluation of forecasts - as this would not entail a fair forecasting exercise - but instead use them for the purpose of appraising the impact of anticipated economic movements on the stock market.

\subsection{Spline-GARCH Component Volatility Model}

There are other two component GARCH models besides the ones proposed in this paper. The direct antecedent of GARCH-MIDAS is the Spline-GARCH model of Engle and Rangel

\footnotetext{
${ }^{7}$ Note that the filter weights are constructed via one single Beta polynomial for each series across leads and lags. While this puts a lot of smoothness conditions it has the advantage that the two-sided scheme remains parsimonious.

${ }^{8}$ See Sheppard (2003) for recent evidence regarding equity (co)variation and economic activity.
} 
(2007) which shares features with the models we discussed in the previous subsections. Many other component models have been suggested - as noted before. We stay within the class of multiplicative models, however, which means we focus exclusively on the SplineGARCH. Both the Spline-GARCH and our models provide a multiplicative decomposition of conditional variance and both specify the short run component as an unit GARCH(1,1) process. 9 In fact, the specification shares equation (3) and (44). The only difference comes from the $\tau$ specification, which is as follows:

$$
\tau_{t}=c \exp \left(w_{0} t+\sum_{k=1}^{K} w_{k}\left(\left(t-t_{k-1}\right)_{+}\right)^{2}\right)
$$

where $\left\{t_{0}=0, t_{1}, t_{2}, \ldots, t_{K}=T\right\}$ denotes a partition of the time horizon $T$ in $(\mathrm{K}+1)$ equallyspaced intervals with the number of knots selected via the BIC criterion 10 We will estimate and compare the performance of both types of models.

\section{Estimation Results}

This is a first of two empirical sections. In this section we cover the estimation of GARCHMIDAS volatility models. In a first subsection we cover models with realized volatility. A second subsection covers those involving macroeconomic variables.

\subsection{Model Selection and Estimation of GARCH-MIDAS models with Realized Volatility}

We take the conventional approach to estimate GARCH-type models, namely QMLE. From Schwert's website, we obtained daily U.S. stock returns over the period from 1885/2/16 to $1962 / 7 / 2$ We also used CRSP daily returns to complete the daily return series up to $2004 / 12 / 31$.

We have quite a long series of data for both daily stock returns (1885-2004) and various

\footnotetext{
${ }^{9}$ One could possibly consider an additive GARCH-MIDAS class of models as well - but this is beyond the scope of the current paper - see however Ghysels and Wang (2003).

${ }^{10}$ See Engle and Rangel (2007) for further details.

${ }^{11}$ For detailed information about this return series, see Schwert (1990).
} 
macroeconomic variables (1884-2004) 12 Due to the concern of potential structural breaks, we will consider various sub-samples and also formally test for breaks. The choice of subsamples follows Schwert (1989), except for the most recent sub-sample. Namely, we consider a split in 1984 to address the so called "Great Moderation," pertaining to the recent decline in macro volatility. Kim and Nelson (1999), McConnell and Perez-Quiros (2000), Blanchard and Simon (2001) and Stock and Watson (2002), find evidence of a regime shift to lower volatility of real macroeconomic activity. Stock and Watson (2002) find the break occurred around 1984 and they conclude that the decline in volatility has occurred in employment growth, consumption growth, inflation and sectoral output growth, as well as in GDP growth in domestic and international data.

As was mentioned in the previous section, there are two variations of GARCH-MIDAS models with RV; GARCH-MIDAS with (1) fixed span and (2) rolling window RV. Furthermore, for each variation, we can consider a large class of models by varying two features. One is the number of years, which we will, henceforth, call 'MIDAS lag years,' spanned in each MIDAS polynomial specification for $\tau_{t} 13$ The other is how to compute RV, weighted by the MIDAS polynomial. In case of fixed span RV, ' $t$ ' in equation (6) can be a month, or a quarter, or a half year. As ' $t$ ' varies, the time span that $\tau_{t}$ is fixed also changes. On the other hand, for the rolling window RV, we can change $N^{\prime}$ in equation (91). Finally, in each case we have a level and a log specification for $\tau$.

We start with the Beta lag structure for the weights in equation (8) and the case where we model $\tau$. The log-likelihood function can be written as:

$$
L L F=-\frac{1}{2} \sum_{t=1}^{T}\left[\log g_{t}(\Phi) \tau_{t}(\Phi)-\frac{\left(r_{t}-\mu\right)^{2}}{g_{t}(\Phi) \tau_{t}(\Phi)}\right]
$$

Figure 1 displays the estimated lag weights of GARCH-MIDAS with fixed span RV for 3 to 5 MIDAS lag years. The figure shows that optimal weights decay to zero around 30 months

\footnotetext{
${ }^{12}$ The data for macroeconomic level variables starts from the third quarter of 1884 and that for estimates of macroeconomic volatility starts from the third quarter of 1885 .

${ }^{13}$ Note that this is not the number of lags $(\mathrm{K})$ in equation (5) or (10). For example, in case of GARCHMIDAS with quarterly fixed span RV (i.e. ' $t$ ' is a quarter), $\tau_{t}$ is fixed for each quarters and 2 MIDAS lag years for this model refers to 8 quarters spanned by 8 lagged quarterly RV's in the MIDAS filter $(i . e . K=8)$. On the other hand, GARCH-MIDAS model with quarterly rolling window RV has $\tau$ component that varies on daily basis with a window length of a quarter (i.e. 65 trading days) for the rolling window of RV's. For this model, 2 MIDAS lag years refer to 500 trading days spanned by 500 lagged quarterly rolling window RV's in the MIDAS filter (i.e. $K=500$ ).
} 
of lags regardless of the choice of ' $t$ ' and length of MIDAS lag year. Similarly, for both fixed span RV and rolling window RV, the optimal value of the log likelihood reaches its plateau for the same MIDAS lag years. Hence, it is enough to take 4 MIDAS lag years to capture reasonable dynamics of $\tau_{t}$ for both GARCH-MIDAS with fixed span RV and rolling window RV. Also, for both the quarterly time span appears to dominate others at most MIDAS lag years. Consequently, we choose "quarterly" time spans and 4 MIDAS lag years for the GARCH-MIDAS model over the full sample period. Another noteworthy feature is that the fixed span RV and rolling window RV models level off at roughly the same value for the $\log$ likelihood function. This indicates that holding $\tau$ constant for some short periods (i.e. quarterly) or let it vary every day does not make much of a difference in terms of likelihood behavior. The fact that we are able to compare these two different specifications is again an attractive feature of our specification. Figures 2 and 3 show the volatility components of GARCH-MIDAS with fixed span RV and rolling window RV respectively. Since the $\tau$ component is of quarterly frequency in Figure 2 and of daily frequency in Figure 3, the latter obviously looks more smooth.

The parameter estimates for these models are shown in the first two rows of Table 2. The results in the table show that almost all parameters are significant. Most of all, $\theta$ is strongly significant. Another interesting feature of the GARCH-MIDAS model appearing in the table is that sums of $\alpha$ and $\beta$ are 0.96721 and 0.96085 for the fixed span RV and rolling window RV cases for the full sample, respectively. These numbers are noticeably less than 1, while in standard GARCH model the sum is typically 1. The same finding is also reported in Engle and Rangel (2007).

As noted earlier, studying long historical samples invariably raises the question about structural breaks. While we will conduct tests for structural breaks, we will also study various sub-samples, assumed to be homogeneous. When we later look into the relationship between stock market volatility and macroeconomic variables, we will also look at subsamples as well as the full sample. Of course, one could argue that the GARCH-MIDAS models accommodate structural breaks via the movements in $\tau$. One can indeed view this as an alternative to segmentation of the sample either via eras, as in Schwert's analysis, or via testing for structural breaks 14 We will turn to the issue of testing for breaks after we report estimates of the various models.

\footnotetext{
${ }^{14}$ For evidence on breaks in (1) volatility see e.g. Lamoureux and Lastrapes (1990), Andreou and Ghysels (2002), Horvath, Kokoszka, and Zhang (2006), (2) the shape of the option smile see e.g. Bates (2000) and (3) the equity premium see e.g. Pastor and Stambaugh (2001), Chang-Jin, Morley, and Nelson (2005).
} 
Table 2 provides parameter estimates for GARCH-MIDAS with quarterly fixed span RV and quarterly rolling window RV. Although we do not report them in the table, we also explored both GARCH-MIDAS specifications with monthly and biannual RV. In some sub-samples, the model with monthly RV or biannually RV offers the best fit, but the quarterly RV case always follows the best model quite closely. Therefore, to keep consistency and comparability with the full sample case, we will choose models with quarterly RV throughout our analysis. All models for sub-samples appearing in Table 2 share the same features as the full sample case: $\theta$ is strongly significant all across specifications in sub-samples and the sums of $\alpha$ and $\beta$ are noticeably smaller than one.

We should also mention that exponential weights instead of the Beta weights in equation (8) yield for all practical purposes the same $\tau$ dynamics. We refrain therefore from reporting all the results with both weighting schemes. It is reassuring, however, that the empirical findings are robust to the choice of MIDAS weights. Since both of our parameterizations involve a single parameter, one can select either one 15

To conclude we briefly turn our attention to the $\log \tau$ specification which is reported in Table 3. Overall the results are similar to the previous specification, except that we typically find lower levels of likelihoods, although the BIC criteria are extremely close.

\subsection{Estimation of GARCH-MIDAS model with macroeconomic variables}

How much does volatility relate to the macro economy and in particular how much does volatility anticipate the future? This is an important question we try to answer. The macroeconomic series we use are drawn from a long historical data set constructed by Schwert (1989) which we augmented with recent data. The series we use are monthly PPI (Producer Price Index) inflation rate and IP (Industrial Production) growth rate. They are the same series used in Schwert (1989) to see the link between stock market volatility and macroeconomic volatility. Compared to Schwert (1989) we do not include the monetary base - since the models we estimated with it yielded results very similar to the models with

\footnotetext{
${ }^{15}$ Note that the original specification for Beta lag structure shown in equation (8) involves two parameters. However, for both of GARCH-MIDAS models with RV, optimal $\omega_{1}$ is always 1 such that the weights are monotonically decreasing over the lags. Hence, for the GARCH-MIDAS models with RV, we set $\omega_{1}=1$, which makes the resulting Beta lag structure involve a single parameter.
} 
inflation. We also did not use interest data as we wanted to use exclusively 'real economy' as opposed to 'financial' series.

Schwert (1989) investigates the relationship between monthly stock market volatility and monthly macroeconomic variables. We decided to stay with a quarterly frequency since the $\log$ likelihood profile of GARCH-MIDAS models with fixed span RV suggested that the quarterly frequency offers both good fit and stability. Hence, we construct quarterly macroeconomic series from the monthly data using a geometric mean of the monthly growth rates. Table 1 provides the summary statistics of the quarterly macroeconomic series.

In addition to the levels of quarterly macroeconomic data, we are also interested in linking stock market volatility to volatility of these quarterly macroeconomic series. In order to estimate volatility of quarterly macroeconomic series, we follow the approach taken by Schwert (1989) 16 We fit the following autoregressive model with four quarterly dummy variables $D_{j t}$ to estimate quarterly macroeconomic volatility. In particular, $\left(\hat{\varepsilon}_{t}\right)^{2}$ from the following regression is used to estimate quarterly macroeconomic volatility (for any macro variable $X)$ :

$$
X_{t}=\sum_{j=1}^{4} \alpha_{j} D_{j t}+\sum_{i=1}^{4} \beta_{i} X_{t-i}+\varepsilon_{t}
$$

To appreciate the time series pattern of the series which enter our model specification, we provide plots of the macroeconomic series in Figures 4 and 5 . The former shows macroeconomic level variables whereas the latter shows macroeconomic volatility variables used in the GARCH-MIDAS specification. We mentioned a few times the issue of structural breaks. Figures 4 and 5 clearly reveal why this is a concern. As far as the levels goes, we note remarkable changes across time, something already noted for instance by Romer (1986). The latter also points out that these changes are in part due to data quality. Macroeconomic series were not very well measured in the early parts of our sample. In a sense, our paper is dealing with noisiness of volatility measures, but does not deal with noisiness in macroeconomic series - an issue much harder to deal with as it largely relates to data collection. In Figure 5 we turn our attention to the volatility of the macroeconomic series, as computed via the above equation (19). Recall that we mentioned the recent work on the "Great Moderation." Clearly we see that the volatility of IP has dramatically been reduced as part of the Great Moderation. The choice of our sub-samples will partly deal

\footnotetext{
${ }^{16}$ We also used a GARCH(1,1) specification to model quarterly volatility of macroeconomic variables and found similar results. Details are available upon request.
} 
with the issue of breaks that are clearly present in the macroeconomic series. In the next section, we will also look more explicitly at testing for structural breaks.

We start with the specifications involving the single series, PPI and IP, for either the level or variance. We focus first on the one-sided filters. The parameter estimates appear in Table 4 for PPI and Table 5 for IP. In each case we took 4 years of lags, or 16 lags.

The most interesting parameter are the slope parameters $\theta_{l / v}$ for level/volatility (l/v) specifications of the MIDAS filter. Consider first the parameter estimates of $\theta_{l}$ for the PPI series. They range from 0.2443 in the pre-1919 sample to 1.0962 for the 1953-1984 sample. Hence, in all cases the parameters are positive - and in all but one case they are statistically significant. This means that more inflation leads to high stock market volatility. For the full sample the parameter estimate is 0.2809 with a t-statistic of 2.56. Since the weighting function with $\omega_{1}=15.65$ and $\omega_{2}=3.37$ puts 0.1375 on the first lag and 0.2755 (which is the maximum weights) on the second lag of PPI level, we find that a one percent increase of inflation at the current quarter would increase the next quarter market volatility by $e^{0.28 \cdot 0.1375}-1 \approx 0.04$ or $4 \%$. If last quarter's inflation increased by $1 \%$, we would see $e^{0.28 \cdot 0.2755}-1 \approx 0.08$ or $8 \%$ increase in market volatility next quarter. For the 1953-1984 sample, the optimal weighting function is characterized by $\omega_{1}=7.40$ and $\omega_{2}=2.67$ and puts 0.0640 on the first lag and 0.1726 (the maximum weight) on the fourth lag. In this case, a one percent increase in current quarter inflation would lead to $e^{1.10 \cdot 0.0640}-1 \approx 0.07$ or $7 \%$ increase in market volatility next quarter. With the similar computations, we would see $21 \%$ increase in market volatility at the current quarter when there was $1 \%$ increase in inflation a year ago. This sample, of course, covers the Volcker and Greenspan years with very little inflation. Turning to the lower panel of 4 reports the impact of inflation uncertainty on stock market volatility. For the full sample the impact is insignificant and looking at the sub-samples we observe that this appears to be mainly due to the Great Depression era. We note again the large parameter estimates for the 1953-1984 sample. It is interesting to note that in terms of economic magnitude - the impact of inflation uncertainty is about the same as the impact of the actual inflation level.

Next we turn to Table 5, which covers IP. The parameter estimates of $\theta_{l}$ range from -1.1870 to -0.0966 . Hence, increases in industrial production decrease volatility - the well known counter cyclical pattern notably reported in Officer (1972) and Schwert (1989). The effect is statistically significant - although the 1985-2004 is only marginal. We find out from the lower panel of Table 5 that IP volatility has a significant positive impact on stock market 
volatility - i.e. business cycle uncertainty matters particularly for the Great Depression and for the 1985-2004 samples.

The parameter estimates of the model which combines the level and volatility of each series, namely models described by equation (14) appears in Table 6. In all cases we observe that the point estimates are quite similar to those obtained with each single series. Yet, the standard errors have increased and most of the measured impacts are no longer statistically significant. This suggests that there is either evidence of co-linearity among the series, or that the volatility models are over-parameterized and difficult to identify 17

To conclude we also cover the two-sided specifications described by equation (15). The parameter estimates appear in Table 7. The top panel pertains to PPI inflation 18 Only with some minor exceptions we find that more inflation - past and future - and more inflation volatility - again past and future - increase stock market volatility. This effect appears significant in the first sub-sample where $\theta_{l / v}^{b}$ is significant, after WWII where anticipated future inflation and past/future inflation volatility enter significantly. The strongest evidence appears for the pre-1984 sample - which included the high inflation period of the 70's. In the sub-sample pertaining to the post-1984 period we find the wrong sign for the effect of inflation on volatility, namely we find a negative sign for $\theta_{l}^{b}$. This sub-sample contains the stock market crash of 1987 and it is also a relatively small sample. Moreover, as will be discussed shortly - the crash of 1987 does not seem to be related to fundamental economic variables. The two combined, i.e. the crash unrelated to fundamentals and a short sample indeed produces anomalous results. We therefore report sample estimates that exclude the crash of 1987, and indeed we find the right positive sign for $\theta_{l}^{b}$, although it is not significant. Note, however, that when we turn our attention to $\theta_{l}^{f}$ with the two-sided filters, we note that in some cases those parameter estimates take on very large values. This result emerges because the forward looking part of the two-sided filter weighting scheme is very small in all such cases. Hence the product of $\theta_{l}^{f}$ and the sum of the filter weights is actually small. This is unfortunately more than a numerical issue. Indeed, it is also an econometric estimation and testing issue that strictly speaking leads to non-standard asymptotics. Technically speaking, if the forward-looking weights of the two-sided filter really add up to zero, then the parameter

\footnotetext{
${ }^{17}$ There appears to be another undesirable estimation problem. Namely, we put an upper bound on the MIDAS Beta polynomial parameters which is equal to 300 - as values above that tend to create numerical instability. We note from Table (14) that the MIDAS polynomial parameters for the models which combines the level and volatility of each series often hit this constraint.

${ }^{18}$ Due to the leads and lags the sample sizes are no longer the same, since those filters involve four years of leads and lags.
} 
$\theta_{l}^{f}$ is actually not identified. Having unidentified parameters under the null of zero weights poses econometric problems that are discussed in the context of MIDAS in Ghysels, Sinko, and Valkanov (2006). Only in a handful of cases, mostly occurring with the PPI series, we find such large point estimates. We will for the sake of simplicity ignore the econometric issues that emerge in this context as the large majority of our parameter estimates are not affected. Obviously, the issue is not only econometric - it also means that future values do not have a significant impact in a few cases.

The second panel of Table 7 confirms - with two-sided filters - the counter cyclical nature of stock market volatility, as parameter estimates of $\theta_{l}^{b}$ are negative. They are significant for the inter-WW period and pre-1984. Future (anticipated) IP has a more ambiguous sign but when it is significant it is clearly negative as well. In contrast, Table 7 also shows that IP volatility increases stock market volatility.

It is also worth examining some plots of sample paths. Figures 6 through 8 display the two-sided IP GARCH-MIDAS models - full sample as well as the Great Depression and Post-WWII sub-samples. The top panel contains the time series paths of $\tau$ and $g * \tau$. The lower panel contains the lag-lead weights for level and volatility of IP in the $\tau$ component according to equation (15). When we consider the models estimated over the respective subsamples we get a better closeup picture. Figure 7 covers the interwar period while Figure 8 covers the last sub-sample from 1985 onwards. In particular in the latter case we see that the October 1987 crash was not driven by economic fundamentals. In all model specifications the large spike in market volatility is picked up by the $g$ component. In great contrast, the Great Depression era was clearly a turbulent time with market volatility linked to economic sources. The weighting schemes that are displayed in the lower panels are also interesting. They show that a great deal of the weight is attributed to the future - which is expected as it reflects the anticipation of economic fundamentals by the stock market.

To conclude we report the parameter estimates of the Spline-GARCH models. The parameter estimates appear in Table 8, The drawback of the Spline-GARCH model selection approach is that the likelihood tends to fluctuate as one increases the number of knots since the position of the knots changes as the number increases. This issue appears to be particularly critical in long time spans, as illustrated in Figure 9. The figure compares the long-run components as measured by $\tau$ in Spline-GARCH model fitted over the full sample and each of sub-samples. The optimal number of knots, with lowest BIC, for the full sample (18902004 ) is seven while those of sub-samples are one (1890-1919), eight (1920-1952), and seven 
(1953-2004), respectively. It will be shown that this seriously affects the performance of the Spline GARCH model.

\section{Appraising the Models and Analyzing the Economic Sources}

In this section we analyze the economic content of volatility models using various new approaches. The first subsection deals with correlation and structural breaks. In the second subsection we study the forecasting performance of the models we estimated. Finally, we measure the contribution of economic sources to expected volatility.

\subsection{Structural Breaks and Correlations}

In this subsection we cover two topics: (1) how do the models handle structural breaks, and (2) how much are the component similar across models. As noted earlier, there is considerable evidence suggesting that there are structural breaks in volatility dynamics, see references in footnote 14 .

So far we considered sub-samples to guard against possible breaks in the volatility models. In this subsection we study whether in fact full sample models are immune to breaks. To address the structural break question we compute a likelihood ratio statistic, comparing the log-likelihood function for the full sample with those of the sub-samples. In particular:

$$
-2\left[L L F_{\text {full }}-\sum_{i=\text { sub-samples }} L L F_{i}\right] \sim \chi^{2}(d f)
$$

where $d f$ is the number of parameters times one minus than the number of sub-samples, which corresponds to the number of restrictions. Since the number of parameters differ across models we adjust the degrees of freedom accordingly. This analysis is confined to GARCH-MIDAS models. It does not include Spline-GARCH since the latter involves a different number of knots in the various sub-samples, and therefore these models are nonnested.

The results are reported in Table 9, The results are easy to summarize, the full sample 
models are not immune to breaks. Hence, the class of models in this paper still leave room for improvement as far as structural stability goes. It also explains why the empirical results involving individual macroeconomic series differ so much across the various sub-samples.

Next, we study the correlations between the various components. Due to space limitations, we do not report correlations in a table, but rather briefly describe their salient features focusing exclusively on the full sample. The highest correlations between $R V$ and any of the estimated macro variables long run components is achieved with the IP level/variance model - which at .36 is slightly less than the Spline-GARCH. The long run component based on inflation yields a somewhat odd negative value, albeit it very small. Likewise, the inflation based long run component also correlates negatively with the IP one. In general, all the IPbased component models feature the highest correlations with any of the RV-based models. Given that the Great Depression is well captured by the IP-based models (recall Figure 7), this result is not surprising.

The results in this section tell us that there is room for improvement. For example, we do not have models that are stable for the full sample. While there is room for improvement, it will be shown in the next subsections that the models we have so far already perform quite well in comparison to existing models and we will also show that the long run component constitutes an important part of volatility forecasts.

\subsection{Forecast comparisons}

Table 10 displays the comparison of forecasting performance over a month, quarter and semester horizon of the two component volatility models discussed so far - using full sample QMLE parameter estimates. The measure of forecasting performance is the mean squared error (henceforth MSE) of conditional variance forecasts compared to realized variance. All cases cover pseudo-out-of-sample forecasts - and pertain to non-overlapping samples of forecasts, either monthly, quarterly or biannual. The results are reported in Table 10. For the purpose of comparison, the GARCH-MIDAS model with rolling window RV is chosen as a benchmark. All forecasts are reported as ratios relative to the latter model's MSE and a ratio below one means an improvement upon the rolling window RV model. For the GARCH-MIDAS with fixed span RV, the Spline-GARCH models and the GARCHMIDAS with macroeconomic variables we keep the $\tau$ component fixed at the level of the last observation prior to prediction. For the GARCH-MIDAS with rolling window RV we 
can easily make a day-forward forecast using $g$ and predetermined $\tau$, yielding $g \tau$, which can be substituted into the MIDAS filter. This process can be iterated forward over the entire prediction horizon. The comparison in Table 10 between GARCH-MIDAS with fixed span RV and rolling window RV reveals that the former is very imprecise - relatively speaking - at short horizons (i.e. monthly horizons), but the disadvantage disappears at longer horizons and ultimately is typically at par or even below par with the latter in terms of MSE's over biannual forecast horizons.

Let us focus first on the full sample forecasting evaluation results - ignoring for the moment the evidence of structural break tests. Moreover, we will also focus mostly on the log RV version as this is directly comparable with the models driven by macroeconomic variables. For the full sample, it is clear that GARCH-MIDAS with rolling log RV is the most attractive two-component model for one month ahead forecasts. Moreover, the fixed span models performs poorly in comparison (again at the one month horizon).

When we increase the forecast horizons, we observe that other models start to improve upon the rolling RV specification. First, it is interesting to note that the fixed sample specification does better than the rolling RV one. At the six month horizon the best model is the GARCH-MIDAS with IP level/variance (and the IP level model following closely). In fact all models involving IP fare better than the models with PPI. For the intermediate horizon - i.e. one quarter ahead - we observe that the RV-based models still dominate for the full sample although the models driven by macroeconomic variables are roughly at par with the benchmark model.

The first sub-sample ending in 1919 is disastrous for the models involving macroeconomic data. A plausible explanation is that the macroeconomic data may not be of good quality to produce good forecasts. Another explanation is that the full sample parameter estimates simply don't fit this sub-sample. As we will show, it is the latter that appears to be the case as the forecasting results with the sub-sample estimates will show later.

For the Great Depression sub-sample there are clearly two models that forecast best at the six month horizon: (1) the fixed sample RV and (2) the GARCH-MIDAS involving IP (level). It is also interesting to note that all models involving macroeconomic series are at par with the statistical models at the one quarter horizon, while all models involving macroeconomic tend to outperform statistical models at the six month horizon. The improvements are roughly $10 \%$ in terms of MSE in the longer horizon case. 
The 1953-2004 and 1985-2004 sub-samples share similar features, i.e. the models involving economic data perform best at the six month horizon, are at par with the RV-based models and under-perform relative to them one month ahead. The orders of magnitude of gains (6 months) and losses (1 month) are also around $10 \%$. Somehow, the 1953-1984 samples proves disastrous for the models involving economic variables. It is also worth noting that while the IP-based models had a slight edge over the PPI-based ones in the earlier sub-samples. This seems no longer the case in the post-WWII period.

To robustify our findings we turn to Table 11 where we focus on the semester horizon, using the sub-sample estimates instead of the full sample estimates. The results in the table clearly show that our main findings remain. The weakest results appear to be for the 19531984 sub-sample - although for this sub-sample the models involving PPI do comparatively well - as this is the era of the oil price shock. It is also worth noting that the 1890-1919 sub-sample shows very good forecast results for all the models driven by macroeconomic variables. Hence, it is clearly the case that for this sub-sample the full sample estimates are highly inadequate.

\subsection{Measuring the contribution of economic sources}

How much of expected volatility can be explained by economic variables? To answer this question we compute the ratio: $\operatorname{Var}\left(\log \left(\tau_{t}^{[M]}\right)\right) / \operatorname{Var}\left(\log \left(\tau_{t}^{[M]} g_{t}^{[M]}\right)\right)$, where $M$ refers to a specific model: GARCH-MIDAS with rolling window RV, with fixed span RV, with Macro volatility, level, and finally Spline-GARCH. We also consider a second ratio,

namely: $\operatorname{Var}\left(\log \left(\tau_{t}^{[M]}\right)\right) / \operatorname{Var}\left(\log \left(\tau_{t}^{[g m-\operatorname{roll} R V]} g_{t}^{[g m-\operatorname{roll} R V]}\right)\right)$, where now all ratios have the same denominator, the GARCH-MIDAS with rolling RV. The choice of this particular expected volatility is motivated by the fact it yields the best predictions and is therefore a good choice as common target. The variance ratio results appear in Table 12, where we cover the full sample as well as the sub-samples 1890-2004, 1890-1919, 1920-1952, 1953-2004, 1953-1984 and 1985-2004.

The full sample estimates tell us that the GARCH-MIDAS model with rolling RV has the most important long run component contribution - over $50 \%$ during the Great Depression era. Among the models involving economic time series we observe that the IP level model contributes to more than $15 \%$ to total volatility in the post-WWII samples, while it is the IP variance model - i.e. output uncertainty is clearly a great source of market volatility 
during the Great Depression era. If we combine level and variance of IP into one model, it is not surprising that we see the largest contribution - over $25 \%$ even in some sub-samples. In contrast, inflation is the great source of the long run component during the 1953-1984 sample - over $35 \%$ of the variance is due to the long run inflation driven component.

The results show that there is clearly room for improvement in terms of explaining volatility with economic variables. Yet, with the two historical series we have, there is quite already significant fraction of variation in expected volatility that can be attributed to economic sources. Obviously, the framework we introduced here allows us to consider other series because we used long historical series our hands were tied due to a small set of available series.

\section{Summary and Conclusion}

In this paper we introduced a new versatile class of component volatility models combining insights of Spline-GARCH and MIDAS filters. This new class allowed us to distinguish shortand long-run sources of volatility and link them directly to economic variables. The new model specifications also relate to the long established use of realized volatility, yet refines these measures through MIDAS filtering.

The approach we propose to measure the contribution of economic variables can be viewed as regression through filtering. Our analysis focused on long historical time series. The long time span limited the set of macroeconomic series available. The class of GARCHMIDAS models can easily handle any set of variables. With more recent data, we could consider liquidity-related series, event-related dummy variable (e.g. announcement effects), etc. Hence, our analysis of GARCH-MIDAS models is not confined to macroeconomic variables as one could conceivably incorporate other economic variables. We leave this for future research.

To assess the economic content we suggest a variance ratio measuring the contribution of economic sources to expected volatility. The results reveal that for the full sample the long run component typically accounts for roughly half of predicted volatility. For the most recent period the results show roughly a $30 \%$ contribution. When the long run component is driven by economic variables the numbers are not so high, except for specific sub-samples such as the Great Depression and some of the post-WWII era. 
What is most encouraging is our findings regarding long term forecasting. We find models with the long term component driven by inflation and industrial production growth are at par in terms of out-of-sample prediction for horizons of one quarter and out-perform pure time series statistical models at longer horizons. The significance of this finding is important and is mostly attributable to the ability of our new models to incorporate macroeconomic variables directly into the specification of volatility dynamics.

Finally, it should also be noted that the idea of component models - short and long run which are driven by economic sources can potentially be extended to multivariate settings - correlation that is. A step in that direction is the work of Colacito, Engle, and Ghysels (2007). 


\section{References}

Adrian, T., and J. Rosenberg, 2004, Stock returns and volatility: Pricing the short-run and long-run components of market risk, Working Paper.

Alizadeh, Sassan, Michael W. Brandt, and Francis Diebold, 2002, Range-based estimation of stochastic volatility models, Journal of Finance 57, 1047-1091.

Andreou, E., and E. Ghysels, 2002, Detecting multiple breaks in financial market volatility dynamics, Journal of Applied Econometrics 17, 579-600.

Bansal, R., and A. Yaron, 2004, Risks for the long run: a potential resolution of asset pricing puzzles, Journal of Finance 59, 1481-1509.

Barberis, N., M. Huang, and T. Santos, 2001, Prospect Theory and Asset Prices, Quarterly Journal of Economics 116, 1-53.

Barndorff-Nielsen, O.E., and N. Shephard, 2002, Econometric analysis of realized volatility and its use in estimating stochastic volatility models, Journal of the Royal Statistical Society, Series B 64, Part 2, 253-280.

Basak, S., and D. Cuoco, 1998, An Equilibrium Model with Restricted Stock Market Participation, Review of Financial Studies 11, 309-341.

Bates, D., 1996, Jumps and stochastic volatility: Exchange rate processes implicit in deutsche mark options, Review of Financial Studies 9, 69-107.

— , 2000, Post-'87 crash fears in the S\&P 500 futures option market, Journal of Econometrics 94, 181-238.

Blanchard, O.J., and J. Simon, 2001, The long and large decline in u.s. output volatility, Brookings Papers on Economic Activity 1, 135-174.

Bollerslev, T., R. Engle, and D. Nelson, 1994, Arch models, Handbook of Econometrics, Engle, R. F., McFadden, D. L. (Eds.), North-Holland, Amsterdam pp. 2959-3038.

Campbell, J., 1991, A variance decomposition for stock returns, The Economic Journal 101, $157-179$. 
- , and J. Cochrane, 1999, By Force of Habit: A Consumption-Based Explanation of Aggregate Stock Market Behavior, Journal of Political Economy 107, 205-251.

Campbell, J., and L. Hentschel, 1992, No news is good news: An asymmetric model of changing volatility in stock returns, Journal of Financial Economics 31, 281-318.

Campbell, J., and R. Shiller, 1988, The dividend-price ratio and expectations of future dividends and discount factors, The Review of Financial Studies 1, 195-228.

Chang-Jin, K., J.C. Morley, and C. R. Nelson, 2005, The Structural Break in the Equity Premium, Journal of Business and Economic Statistics 23, 181-191.

Chernov, M., R. Gallant, E. Ghysels, and G. Tauchen, 2003, Alternative models for stock price dynamics, Journal of Econometrics 116, 225-257.

Chordia, T., R. Roll, and A. Subrahmanyam, 2002, Order imbalance, liquidity, and market returns, Journal of Financial Economics 65, 111-130.

Colacito, R., R. Engle, and E. Ghysels, 2007, A component model for dynamic correlations, Discussion Paper, NYU and UNC.

Ding, Z., and C. Granger, 1996, Modeling volatility persistence of speculative returns: A new approach, Journal of Econometrics 73, 185-215.

Drost, F.C., and B.M.J. Werker, 1996, Closing the garch gap: Continuous time garch modeling, Journal of Econometrics 74, 31-57.

Engle, R., 1982, Autoregressive conditional heteroskedasticity with estimates of the variance of u.k. inflation, Econometrica 50, 987-1008.

— , and G. Lee, 1999, A permanent and transitory component model of stock return volatility, R. Engle and H. White (ed.) Cointegration, Causality, and Forecasting: $A$ Festschrift in Honor of Clive W. J. Granger, Oxford University Press pp. 475-497.

Engle, R., and J. Rangel, 2007, The spline garch model for low frequency volatility and its global macroeconomic causes, The Review of Financial Studies forthcoming.

Fama, E., and K. French, 1989, Business Conditions and Expected Returns on Stock and Bonds, Journal of Financial Economics 25, 23-49. 
Ferson, W., and C. Harvey, 1991, The Variation of Economic Risk Premiums, Journal of Political Economy 99, 385-415.

Foster, D.P., and D.B. Nelson, 1996, Continuous record asymptotics for rolling sample variance estimators, Econometrica 64, 139-174.

Gallant, A. Ronald, C.-T. Hsu, and George Tauchen, 1999, Using daily range data to calibrate volatility diffusions and extract the forward integrated variance, Review of Economic Statistics 81, 617-631.

Garcia, R., E. Ghysels, and E. Renault, 2003, The econometrics of option pricing, forthcoming in Handbook of Financial Econometrics, Y. Ait-Sahalia and L. P. Hansen (eds.), North Holland, Amsterdam.

Ghysels, E., A. Harvey, and E. Renault, 1996, Stochastic volatility in handbook of statistics, maddala, g. s., rao, c. r. (eds.), north holland, amsterdam, Handbook of Econometrics, Engle, R. F., McFadden, D. L. (Eds.), North-Holland, Amsterdam pp. 119-191.

Ghysels, Eric, Pedro Santa-Clara, and Rossen Valkanov, 2005, There is a risk-return tradeoff after all, Journal of Financial Economics 76, 509-548.

Ghysels, Eric, Arthur Sinko, and Rossen Valkanov, 2006, MIDAS Regressions: Further Results and New Directions, Econometric Reviews 26, 53-90.

Ghysels, Eric, and Fangfang Wang, 2003, Statistical Inference for Volatility Component Models, Discussion Paper, UNC.

Horvath, L., P. Kokoszka, and A. Zhang, 2006, Monitoring constancy of variance in conditionally heteroskedastic time series, Econometric Theory 22, 373-402.

Jacod, J., 1994, Limit of random measures associated with the increments of a brownian semimartingale, Preprint number 120, Laboratoire de Probabilités, Université Pierre et Marie Curie, Paris.

Kim, C.J., and C.R. Nelson, 1999, Has the economy become more stable? a bayesian approach based on a markov-switching model of the business cycle, The Review of Economics and Statistics 81, 608-616.

Lamoureux, C., and W. Lastrapes, 1990, Persistence in Variance, Structural GARCH Model, Journal of Business and Economic Statistics 8, 225-234. 
McConnell, M.M., and G. Perez-Quiros, 2000, Output fluctuations in the united states: What has changed since the early 1980s?, American Economic Review 90(5), 1464-1476.

Merton, Robert C., 1980, On estimating the expected return on the market: An exploratory investigation, Journal of Financial Economics 8, 323-361.

Nelson, D., 1990, Arch models as diffusion approximations, Journal of Econometrics 45, $7-38$.

Officer, R., 1972, The variability of the market factor of the new york stock exchange, Journal of Business 46, 434-453.

Pastor, L., and R. Stambaugh, 2001, The equity premium and structural Breaks, Journal of Finance 56, 1207-1239.

Romer, Christina D., 1986, Is the stabilization of the postwas economy a figment of the data?, The American Economic Review 76, 314-334.

Schwert, G. W., 1989, Why does stock market volatility change over time?, Journal of Finance 44, 1207-1239.

— 1990, Indexes of u.s. stock prices from 1802 to 1987, Journal of Business 63, 399426.

Shephard, N., 2005, Stochastic Volatility: Selected Readings (Oxford University Press).

Sheppard, K., 2003, Economic Factors and the Covariance of Equity Returns, Discussion Paper, Nuffield College, Oxford.

Sims, Christopher A., 1972, Money, income, and causality, The American Economic Review $62,540-552$.

Stock, J.H., and M.W. Watson, 2002, Has the Business Cycle Change and Why? in NBER Macroeconomics Annual: 2002, ed. by M. Gertler, and K. Rogoff (MIT Press, Cambridge, MA).

Tauchen, G., 2005, Stochastic Volatility in General Equilibrium, Duke University working paper. 
Table 1: Summary Statistics for U.S. Daily Stock Returns and Quarterly Macroeconomic Level Variables

Daily U.S. stock return series from 1885 to 2004 were constructed from William Schwert's website and the CRSP dataset. The macroeconomic variables are Producer Price Index inflation rate (PPI) and Industrial Production growth rate (IP). Quarterly macroeconomic rates are obtained by taking geometric means of monthly rates.

\begin{tabular}{|c|c|c|c|c|c|c|c|c|c|c|}
\hline Sample & Variable & Mean & STD & Skewness & Kurtosis & Variable & Mean & STD & Skewness & Kurtosis \\
\hline Full Sample & $\begin{array}{l}\text { Daily stock returns } \\
\text { IP }\end{array}$ & $\begin{array}{l}0.00034 \\
0.00335\end{array}$ & $\begin{array}{l}0.01026 \\
0.01759\end{array}$ & $\begin{array}{c}-0.13 \\
0.12\end{array}$ & $\begin{array}{l}21.06 \\
12.77\end{array}$ & PPI & 0.00178 & 0.01017 & -1.11 & 16.18 \\
\hline $1884-1919$ & $\begin{array}{l}\text { Daily stock returns } \\
\text { IP }\end{array}$ & $\begin{array}{l}0.00027 \\
0.00461\end{array}$ & $\begin{array}{l}0.00846 \\
0.02067\end{array}$ & $\begin{array}{c}-0.32 \\
0.33\end{array}$ & $\begin{array}{l}9.99 \\
7.44\end{array}$ & PPI & 0.00198 & 0.01161 & 0.71 & 3.87 \\
\hline $1920-1952$ & $\begin{array}{l}\text { Daily stock returns } \\
\text { IP }\end{array}$ & $\begin{array}{l}0.00038 \\
0.00314\end{array}$ & $\begin{array}{l}0.01315 \\
0.02453\end{array}$ & $\begin{array}{c}0.29 \\
-0.10\end{array}$ & $\begin{array}{c}16.24 \\
8.31\end{array}$ & PPI & 0.00025 & 0.01395 & -1.84 & 13.77 \\
\hline $1953-2004$ & $\begin{array}{l}\text { Daily stock returns } \\
\text { IP }\end{array}$ & $\begin{array}{l}0.00036 \\
0.00262\end{array}$ & $\begin{array}{l}0.00903 \\
0.00675\end{array}$ & $\begin{array}{l}-0.93 \\
-1.10\end{array}$ & $\begin{array}{c}28.47 \\
6.27\end{array}$ & PPI & 0.00262 & 0.00480 & 1.10 & 7.03 \\
\hline 1953-1984 & $\begin{array}{l}\text { Daily stock returns } \\
\text { IP }\end{array}$ & $\begin{array}{l}0.00031 \\
0.00280\end{array}$ & $\begin{array}{l}0.00774 \\
0.00814\end{array}$ & $\begin{array}{c}0.06 \\
-1.04\end{array}$ & $\begin{array}{l}7.03 \\
4.85\end{array}$ & PPI & 0.00329 & 0.00474 & 1.74 & 7.14 \\
\hline 1985-2004 & $\begin{array}{l}\text { Daily stock returns } \\
\text { IP }\end{array}$ & $\begin{array}{l}0.00045 \\
0.00233\end{array}$ & $\begin{array}{l}0.01077 \\
0.00357\end{array}$ & $\begin{array}{l}-1.47 \\
-0.72\end{array}$ & $\begin{array}{c}33.54 \\
3.39\end{array}$ & PPI & 0.00154 & 0.00473 & 0.22 & 6.15 \\
\hline
\end{tabular}




\section{Table 2: Parameter Estimates for GARCH-MIDAS with Realized Variance}

GARCH-MIDAS models with various specifications are fitted using QMLE. The model specification has different interpretations for GARCHMIDAS model with fixed span $R V$ and the one with rolling window $R V$. The 'Qtr/4yr' model with fixed span RV sets its long run component $\tau$ fixed at a quarterly frequency and uses 16 lagged quarterly RV's (i.e. RV's spanning past 4 years) to model the $\tau$ filter. In contrast the GARCH-MIDAS model with rolling window RV uses quarterly rolling window RV's, i.e. sum of 65 (approximate number of days in a quarter) squared daily returns, that cover past 4 years to model the $\tau$. For various sample choices and GARCH-MIDAS with (fixed span/rolling $\mathrm{RV})$, the specification of $\mathrm{Qtr} / 4 \mathrm{yr}$ is commonly taken. The $\omega$ in the table is $\omega_{2}$ as the optimal $\omega_{1}$ is 1 such that the optimal weights are monotonically decreasing over the lags. The numbers in the parenthesis are robust $t$-stats computed with HAC standard errors. LLF is the optimal log-likelihood function value and BIC is the Bayesian Information Criterion.

\begin{tabular}{|c|c|c|c|c|c|c|c|c|}
\hline Sample & MIDAS Regressor & $\mu$ & $\alpha$ & $\beta$ & $\theta$ & $\omega$ & $m$ & $\mathrm{LLF} / \mathrm{BIC}$ \\
\hline \multirow[t]{2}{*}{ 1890-2004 } & Fixed RV & $\begin{array}{c}0.00058 \\
(14.92)\end{array}$ & $\begin{array}{c}0.10722 \\
(13.12)\end{array}$ & $\begin{array}{c}0.85999 \\
(81.56)\end{array}$ & $\begin{array}{c}0.00966 \\
(20.11)\end{array}$ & $\begin{array}{c}4.51517 \\
(3.25)\end{array}$ & $\begin{array}{c}0.00003 \\
(17.74)\end{array}$ & $\begin{array}{c}106878.7 \\
-6.7499\end{array}$ \\
\hline & Rolling RV & $\begin{array}{c}0.00058 \\
(12.89)\end{array}$ & $\begin{array}{c}0.10994 \\
(9.83)\end{array}$ & $\begin{array}{c}0.85091 \\
(40.16)\end{array}$ & $\begin{array}{c}0.01112 \\
(21.28)\end{array}$ & $\begin{array}{c}4.40323 \\
(1.13)\end{array}$ & $\begin{array}{c}0.00003 \\
(14.85)\end{array}$ & $\begin{array}{c}106883.5 \\
-6.7502\end{array}$ \\
\hline \multirow[t]{2}{*}{ 1890-1919 } & Fixed RV & $\begin{array}{c}0.00054 \\
(7.26)\end{array}$ & $\begin{array}{c}0.15368 \\
(9.57)\end{array}$ & $\begin{array}{c}0.78035 \\
(39.35)\end{array}$ & $\begin{array}{c}0.00462 \\
(-7.96)\end{array}$ & $\begin{array}{c}236.68483 \\
(30.32)\end{array}$ & $\begin{array}{c}0.00005 \\
(14.58)\end{array}$ & $\begin{array}{l}30603.5 \\
-6.9161\end{array}$ \\
\hline & Rolling RV & $\begin{array}{c}0.00052 \\
(7.12)\end{array}$ & $\begin{array}{c}0.15732 \\
(13.86)\end{array}$ & $\begin{array}{c}0.75886 \\
(34.45)\end{array}$ & $\begin{array}{c}0.00741 \\
(10.77)\end{array}$ & $\begin{array}{c}29.82684 \\
(1.59)\end{array}$ & $\begin{array}{c}0.00004 \\
(12.49)\end{array}$ & $\begin{array}{l}30612.4 \\
-6.9181\end{array}$ \\
\hline \multirow[t]{2}{*}{ 1920-1952 } & Fixed RV & $\begin{array}{c}0.00076 \\
(9.59)\end{array}$ & $\begin{array}{c}0.10643 \\
(8.74)\end{array}$ & $\begin{array}{c}0.84806 \\
(53.67)\end{array}$ & $\begin{array}{l}0.00901 \\
(-13.43)\end{array}$ & $\begin{array}{c}14.61377 \\
(49.00)\end{array}$ & $\begin{array}{c}0.00004 \\
(11.40)\end{array}$ & $\begin{array}{l}31251.3 \\
-6.4200\end{array}$ \\
\hline & Rolling RV & $\begin{array}{c}0.00076 \\
(9.26)\end{array}$ & $\begin{array}{c}0.10499 \\
(11.15)\end{array}$ & $\begin{array}{c}0.85280 \\
(62.16)\end{array}$ & $\begin{array}{c}0.01102 \\
(15.10)\end{array}$ & $\begin{array}{c}3.73909 \\
(3.44)\end{array}$ & $\begin{array}{c}0.00003 \\
(7.30)\end{array}$ & $\begin{array}{l}31270.8 \\
-6.4240\end{array}$ \\
\hline
\end{tabular}

Table continued on next page ... 
Table 2 continued

\begin{tabular}{|c|c|c|c|c|c|c|c|c|}
\hline Sample & MIDAS Regressor & $\mu$ & $\alpha$ & $\beta$ & $\theta$ & $\omega$ & $m$ & $\mathrm{LLF} / \mathrm{BIC}$ \\
\hline \multirow[t]{2}{*}{ 1953-2004 } & Fixed RV & $\begin{array}{c}0.00053 \\
(8.90)\end{array}$ & $\begin{array}{c}0.08820 \\
(7.18)\end{array}$ & $\begin{array}{c}0.89231 \\
(55.52)\end{array}$ & $\begin{array}{c}0.01179 \\
(-7.81)\end{array}$ & $\begin{array}{c}3.18549 \\
(1.49)\end{array}$ & $\begin{array}{c}0.00003 \\
(5.39)\end{array}$ & $\begin{array}{l}45051.8 \\
-6.8790\end{array}$ \\
\hline & Rolling RV & $\begin{array}{c}0.00053 \\
(7.10)\end{array}$ & $\begin{array}{c}0.08914 \\
(5.74)\end{array}$ & $\begin{array}{c}0.88873 \\
(37.80)\end{array}$ & $\begin{array}{c}0.01187 \\
(9.57)\end{array}$ & $\begin{array}{c}3.04689 \\
(1.04)\end{array}$ & $\begin{array}{c}0.00002 \\
(5.78)\end{array}$ & $\begin{array}{l}45050.7 \\
-6.8789\end{array}$ \\
\hline \multirow[t]{2}{*}{ 1953-1984 } & Fixed RV & $\begin{array}{c}0.00047 \\
(5.30)\end{array}$ & $\begin{array}{c}0.08482 \\
(6.30)\end{array}$ & $\begin{array}{c}0.89993 \\
(43.07)\end{array}$ & $\begin{array}{c}0.00720 \\
(-3.09)\end{array}$ & $\begin{array}{c}4.15859 \\
(2.15)\end{array}$ & $\begin{array}{c}0.00004 \\
(3.56)\end{array}$ & $\begin{array}{l}28571.6 \\
-7.0980\end{array}$ \\
\hline & Rolling RV & $\begin{array}{c}0.00048 \\
(1.06)\end{array}$ & $\begin{array}{c}0.09256 \\
(6.20)\end{array}$ & $\begin{array}{c}0.88041 \\
(33.07)\end{array}$ & $\begin{array}{c}0.01094 \\
(3.58)\end{array}$ & $\begin{array}{c}6.24408 \\
(36021.77)\end{array}$ & $\begin{array}{l}0.00002 \\
(843.32)\end{array}$ & $\begin{array}{l}28576.6 \\
-7.0992\end{array}$ \\
\hline \multirow[t]{2}{*}{ 1985-2004 } & Fixed RV & $\begin{array}{c}0.00068 \\
(5.81)\end{array}$ & $\begin{array}{c}0.09183 \\
(3.38)\end{array}$ & $\begin{array}{c}0.88155 \\
(24.60)\end{array}$ & $\begin{array}{c}0.01029 \\
(-4.86)\end{array}$ & $\begin{array}{c}3.50909 \\
(0.59)\end{array}$ & $\begin{array}{c}0.00004 \\
(4.68)\end{array}$ & $\begin{array}{r}16490.1 \\
-6.5245\end{array}$ \\
\hline & Rolling RV & $\begin{array}{c}0.00070 \\
(5.75)\end{array}$ & $\begin{array}{c}0.10285 \\
(3.27)\end{array}$ & $\begin{array}{c}0.83415 \\
(14.29)\end{array}$ & $\begin{array}{c}0.01030 \\
(8.91)\end{array}$ & $\begin{array}{c}13.67546 \\
(1.40)\end{array}$ & $\begin{array}{c}0.00003 \\
(6.04)\end{array}$ & $\begin{array}{l}16486.4 \\
-6.5230\end{array}$ \\
\hline
\end{tabular}


Table 3: Parameter Estimates for GARCH-MIDAS with Realized Variance - Log Specification

GARCH-MIDAS models with various specifications are fitted via QMLE. The specifications are the same as in Table 2, with the difference that the long run component $\tau$ is specified in terms of logs as in equation (11). The numbers in the parenthesis are robust $t$-stats computed with HAC standard errors. LLF is the optimal log-likelihood function value and BIC is the Bayesian Information Criterion.

\begin{tabular}{|c|c|c|c|c|c|c|c|c|}
\hline Sample & MIDAS Regressor & $\mu$ & $\alpha$ & $\beta$ & $\theta$ & $\omega$ & $m$ & $\mathrm{LLF} / \mathrm{BIC}$ \\
\hline \multirow[t]{2}{*}{ 1890-2004 } & Fixed RV & $\begin{array}{c}0.00058 \\
(13.35)\end{array}$ & $\begin{array}{c}0.10312 \\
(14.35)\end{array}$ & $\begin{array}{c}0.87382 \\
(93.38)\end{array}$ & $\begin{array}{c}50.21358 \\
(25.42)\end{array}$ & $\begin{array}{c}3.39990 \\
(3.98)\end{array}$ & $\begin{array}{l}-9.66612 \\
(-129.11)\end{array}$ & $\begin{array}{c}106848.4 \\
-6.7480\end{array}$ \\
\hline & Rolling RV & $\begin{array}{c}0.00058 \\
(12.92)\end{array}$ & $\begin{array}{c}0.10332 \\
(15.96)\end{array}$ & $\begin{array}{c}0.87322 \\
(113.33)\end{array}$ & $\begin{array}{c}56.26263 \\
(18.33)\end{array}$ & $\begin{array}{c}2.26791 \\
(3.90)\end{array}$ & $\begin{array}{l}-9.67914 \\
(-112.45)\end{array}$ & $\begin{array}{c}106846.1 \\
-6.7478\end{array}$ \\
\hline \multirow[t]{2}{*}{ 1890-1919 } & Fixed RV & $\begin{array}{c}0.00054 \\
(7.60)\end{array}$ & $\begin{array}{c}0.15233 \\
(9.32)\end{array}$ & $\begin{array}{c}0.78688 \\
(36.43)\end{array}$ & $\begin{array}{c}46.68378 \\
(5.19)\end{array}$ & $\begin{array}{c}35.41077 \\
(1.37)\end{array}$ & $\begin{array}{c}-9.79615 \\
(-92.38)\end{array}$ & $\begin{array}{l}30599.8 \\
-6.9153\end{array}$ \\
\hline & Rolling RV & $\begin{array}{c}0.00053 \\
(7.67)\end{array}$ & $\begin{array}{c}0.15472 \\
(10.23)\end{array}$ & $\begin{array}{c}0.77506 \\
(37.59)\end{array}$ & $\begin{array}{c}74.41938 \\
(6.10)\end{array}$ & $\begin{array}{c}18.66361 \\
(2.53)\end{array}$ & $\begin{array}{r}-9.91757 \\
(-90.69)\end{array}$ & $\begin{array}{l}30606.2 \\
-6.9167\end{array}$ \\
\hline \multirow[t]{2}{*}{ 1920-1952 } & Fixed RV & $\begin{array}{c}0.00075 \\
(9.47)\end{array}$ & $\begin{array}{c}0.10398 \\
(10.87)\end{array}$ & $\begin{array}{c}0.86611 \\
(70.43)\end{array}$ & $\begin{array}{c}43.89592 \\
(13.47)\end{array}$ & $\begin{array}{c}3.90938 \\
(4.15)\end{array}$ & $\begin{array}{c}-9.58621 \\
(-72.64)\end{array}$ & $\begin{array}{l}31260.1 \\
-6.4218\end{array}$ \\
\hline & Rolling RV & $\begin{array}{c}0.00075 \\
(9.50)\end{array}$ & $\begin{array}{c}0.10383 \\
(10.33)\end{array}$ & $\begin{array}{c}0.86633 \\
(69.17)\end{array}$ & $\begin{array}{c}49.23552 \\
(12.60)\end{array}$ & $\begin{array}{c}2.55245 \\
(4.48)\end{array}$ & $\begin{array}{c}-9.57460 \\
(-72.56)\end{array}$ & $\begin{array}{l}31259.5 \\
-6.4217\end{array}$ \\
\hline
\end{tabular}

Table continued on next page ... 
Table 3 continued

\begin{tabular}{|c|c|c|c|c|c|c|c|c|}
\hline Sample & MIDAS Regressor & $\mu$ & $\alpha$ & $\beta$ & $\theta$ & $\omega$ & $m$ & $\mathrm{LLF} / \mathrm{BIC}$ \\
\hline \multirow[t]{2}{*}{ 1953-2004 } & Fixed RV & $\begin{array}{c}0.00052 \\
(6.91)\end{array}$ & $\begin{array}{c}0.08350 \\
(6.82)\end{array}$ & $\begin{array}{c}0.90344 \\
(67.39)\end{array}$ & $\begin{array}{c}121.95035 \\
(4.36)\end{array}$ & $\begin{array}{c}1.37404 \\
(2.87)\end{array}$ & $\begin{array}{r}-9.98047 \\
(-44.59)\end{array}$ & $\begin{array}{r}45049.7 \\
-6.8787\end{array}$ \\
\hline & Rolling RV & $\begin{array}{c}0.00052 \\
(7.37)\end{array}$ & $\begin{array}{c}0.08295 \\
(6.28)\end{array}$ & $\begin{array}{c}0.90442 \\
(61.87)\end{array}$ & $\begin{array}{c}105.59277 \\
(3.50)\end{array}$ & $\begin{array}{c}1.20684 \\
(3.13)\end{array}$ & $\begin{array}{c}-9.90959 \\
(-40.22)\end{array}$ & $\begin{array}{l}45045.8 \\
-6.8781\end{array}$ \\
\hline \multirow[t]{2}{*}{ 1953-1984 } & Fixed RV & $\begin{array}{c}0.00047 \\
(5.61)\end{array}$ & $\begin{array}{c}0.08361 \\
(7.63)\end{array}$ & $\begin{array}{c}0.90223 \\
(53.76)\end{array}$ & $\begin{array}{c}102.03849 \\
(1.39)\end{array}$ & $\begin{array}{c}3.60318 \\
(2.50)\end{array}$ & $\begin{array}{c}-10.01656 \\
(-23.28)\end{array}$ & $\begin{array}{r}28571.6 \\
-7.0980\end{array}$ \\
\hline & Rolling RV & $\begin{array}{c}0.00047 \\
(5.81)\end{array}$ & $\begin{array}{c}0.08691 \\
(7.99)\end{array}$ & $\begin{array}{c}0.89428 \\
(60.77)\end{array}$ & $\begin{array}{c}130.72881 \\
(4.31)\end{array}$ & $\begin{array}{c}4.30043 \\
(2.96)\end{array}$ & $\begin{array}{c}-10.19076 \\
(-42.30)\end{array}$ & $\begin{array}{r}28574.2 \\
-7.0986\end{array}$ \\
\hline \multirow[t]{2}{*}{$1985-2004$} & Fixed RV & $\begin{array}{c}0.00067 \\
(5.71)\end{array}$ & $\begin{array}{c}0.08874 \\
(3.10)\end{array}$ & $\begin{array}{c}0.89184 \\
(25.05)\end{array}$ & $\begin{array}{c}85.69048 \\
(2.76)\end{array}$ & $\begin{array}{c}1.75511 \\
(1.40)\end{array}$ & $\begin{array}{c}-9.68758 \\
(-31.68)\end{array}$ & $\begin{array}{r}16487.2 \\
-6.5233\end{array}$ \\
\hline & Rolling RV & $\begin{array}{c}0.00067 \\
(6.01)\end{array}$ & $\begin{array}{c}0.08790 \\
(2.97)\end{array}$ & $\begin{array}{c}0.89373 \\
(26.05)\end{array}$ & $\begin{array}{c}73.99919 \\
(2.55)\end{array}$ & $\begin{array}{c}1.30213 \\
(2.02)\end{array}$ & $\begin{array}{c}-9.60975 \\
(-30.14)\end{array}$ & $\begin{array}{r}16484.3 \\
-6.5222\end{array}$ \\
\hline
\end{tabular}




\section{Table 4: Parameter Estimates of GARCH-MIDAS with PPI}

GARCH-MIDAS models with various specifications are fitted via QMLE. The specifications appear in equations (12) for the level and (13) for the variance. Quarterly macroeconomic level variable is obtained by taking geometric mean of monthly rates. The corresponding variance is estimated from equation (19), a similar approach to Schwert (1989). For both specifications with macroeconomic level and variance in the MIDAS filter, 16 lags are taken to model $\log \tau_{t} . \theta_{l}$ and $\theta_{v}$ are rescaled by multiplication of $10^{-2}$ and $10^{-4}$ to make the macro level variables represented in percentage unit. The numbers in the parenthesis are robust $t$-stats computed with HAC standard errors.

\begin{tabular}{|c|c|c|c|c|c|c|c|}
\hline \multirow[b]{2}{*}{ Sample } & \multicolumn{7}{|c|}{ Level of PPI } \\
\hline & $\mu$ & $\alpha$ & $\beta$ & $\theta_{l}$ & $\omega_{l, 1}$ & $\omega_{l, 2}$ & $m$ \\
\hline 1890-2004 & $\begin{array}{c}0.00056 \\
(12.18)\end{array}$ & $\begin{array}{c}0.09539 \\
(13.12)\end{array}$ & $\begin{array}{c}0.89444 \\
(122.20)\end{array}$ & $\begin{array}{c}0.28091 \\
(2.56)\end{array}$ & $\begin{array}{c}15.65280 \\
(0.92)\end{array}$ & $\begin{array}{c}3.36746 \\
(1.19)\end{array}$ & $\begin{array}{c}-9.12962 \\
(-65.34)\end{array}$ \\
\hline $1890-1919$ & $\begin{array}{c}0.00053 \\
(7.10)\end{array}$ & $\begin{array}{c}0.14355 \\
(8.73)\end{array}$ & $\begin{array}{c}0.81297 \\
(37.41)\end{array}$ & $\begin{array}{c}0.24431 \\
(2.44)\end{array}$ & $\begin{array}{c}13.23874 \\
(1.14)\end{array}$ & $\begin{array}{c}3.57186 \\
(0.95)\end{array}$ & $\begin{array}{c}-9.54223 \\
(-84.40)\end{array}$ \\
\hline 1920-1952 & $\begin{array}{c}0.00073 \\
(8.59)\end{array}$ & $\begin{array}{c}0.09379 \\
(8.59)\end{array}$ & $\begin{array}{c}0.89822 \\
(79.16)\end{array}$ & $\begin{array}{c}0.22639 \\
(2.32)\end{array}$ & $\begin{array}{c}16.33749 \\
(1.03)\end{array}$ & $\begin{array}{c}2.52484 \\
(0.97)\end{array}$ & $\begin{array}{c}-8.72243 \\
(-30.69)\end{array}$ \\
\hline 1953-2004 & $\begin{array}{c}0.00051 \\
(8.01)\end{array}$ & $\begin{array}{c}0.07720 \\
(6.07)\end{array}$ & $\begin{array}{c}0.91517 \\
(68.34)\end{array}$ & $\begin{array}{c}0.86818 \\
(2.14)\end{array}$ & $\begin{array}{c}25.47665 \\
(0.43)\end{array}$ & $\begin{array}{c}6.97972 \\
(0.64)\end{array}$ & $\begin{array}{c}-9.44728 \\
(-33.77)\end{array}$ \\
\hline 1953-1984 & $\begin{array}{c}0.00047 \\
(4.93)\end{array}$ & $\begin{array}{c}0.08202 \\
(7.80)\end{array}$ & $\begin{array}{c}0.90040 \\
(58.92)\end{array}$ & $\begin{array}{c}1.09618 \\
(4.50)\end{array}$ & $\begin{array}{c}7.39798 \\
(1.89)\end{array}$ & $\begin{array}{c}2.67376 \\
(3.10)\end{array}$ & $\begin{array}{c}-10.03831 \\
(-48.36)\end{array}$ \\
\hline \multirow[t]{2}{*}{ 1985-2004 } & $\begin{array}{c}0.00065 \\
(5.35)\end{array}$ & $\begin{array}{c}0.07746 \\
(2.91)\end{array}$ & $\begin{array}{c}0.91406 \\
(33.42)\end{array}$ & $\begin{array}{c}0.75169 \\
(0.82)\end{array}$ & $\begin{array}{c}73.15156 \\
(0.56)\end{array}$ & $\begin{array}{c}19.27176 \\
(0.57)\end{array}$ & $\begin{array}{c}-9.01668 \\
(-24.85)\end{array}$ \\
\hline & \multicolumn{7}{|c|}{ Variance of PPI } \\
\hline Sample & $\mu$ & $\alpha$ & $\beta$ & $\theta_{v}$ & $\omega_{v, 1}$ & $\omega_{v, 2}$ & $m$ \\
\hline 1890-2004 & $\begin{array}{c}0.00056 \\
(11.48)\end{array}$ & $\begin{array}{c}0.09486 \\
(12.41)\end{array}$ & $\begin{array}{c}0.89532 \\
(111.20)\end{array}$ & $\begin{array}{c}0.05428 \\
(1.40)\end{array}$ & $\begin{array}{c}1.00000 \\
(0.28)\end{array}$ & $\begin{array}{c}1.00000 \\
(0.26)\end{array}$ & $\begin{array}{c}-9.10021 \\
(-60.47)\end{array}$ \\
\hline 1890-1919 & $\begin{array}{c}0.00053 \\
(7.16)\end{array}$ & $\begin{array}{c}0.14346 \\
(8.59)\end{array}$ & $\begin{array}{c}0.81063 \\
(36.21)\end{array}$ & $\begin{array}{c}0.19544 \\
(3.16)\end{array}$ & $\begin{array}{c}8.31992 \\
(1.15)\end{array}$ & $\begin{array}{c}1.40548 \\
(0.91)\end{array}$ & $\begin{array}{c}-9.74430 \\
(-74.32)\end{array}$ \\
\hline 1920-1952 & $\begin{array}{c}0.00073 \\
(3.71)\end{array}$ & $\begin{array}{c}0.09337 \\
(6.92)\end{array}$ & $\begin{array}{c}0.89955 \\
(84.13)\end{array}$ & $\begin{array}{c}-0.03908 \\
(-0.12)\end{array}$ & $\begin{array}{c}11.09956 \\
(0.95)\end{array}$ & $\begin{array}{c}1.00000 \\
(0.05)\end{array}$ & $\begin{array}{c}-8.57764 \\
(-9.32)\end{array}$ \\
\hline 1953-2004 & $\begin{array}{c}0.00051 \\
(7.04)\end{array}$ & $\begin{array}{c}0.07650 \\
(7.03)\end{array}$ & $\begin{array}{c}0.91562 \\
(79.82)\end{array}$ & $\begin{array}{c}0.65945 \\
(2.03)\end{array}$ & $\begin{array}{c}16.24953 \\
(0.99)\end{array}$ & $\begin{array}{c}4.06291 \\
(1.40)\end{array}$ & $\begin{array}{c}-9.39528 \\
(-39.53)\end{array}$ \\
\hline 1953-1984 & $\begin{array}{c}0.00047 \\
(6.12)\end{array}$ & $\begin{array}{c}0.07970 \\
(9.31)\end{array}$ & $\begin{array}{c}0.90643 \\
(88.04)\end{array}$ & $\begin{array}{c}1.27777 \\
(3.80)\end{array}$ & $\begin{array}{c}19.68184 \\
(1.31)\end{array}$ & $\begin{array}{c}4.95236 \\
(1.62)\end{array}$ & $\begin{array}{c}-9.87795 \\
(-47.34)\end{array}$ \\
\hline 1985-2004 & $\begin{array}{c}0.00066 \\
(3.53)\end{array}$ & $\begin{array}{c}0.07845 \\
(2.59)\end{array}$ & $\begin{array}{c}0.91371 \\
(31.38)\end{array}$ & $\begin{array}{c}0.85993 \\
(1.29)\end{array}$ & $\begin{array}{c}30.76334 \\
(0.40)\end{array}$ & $\begin{array}{c}300.00000 \\
(0.36)\end{array}$ & $\begin{array}{c}-9.03304 \\
(-10.99)\end{array}$ \\
\hline
\end{tabular}




\section{Table 5: Parameter Estimates of GARCH-MIDAS with IP}

GARCH-MIDAS models with various specifications are fitted via QMLE. The specifications appear in equations (12) for the level and (13) for the variance. Quarterly macroeconomic level variable is obtained by taking geometric mean of monthly rates. The corresponding variance is estimated from equation (19), a similar approach to Schwert (1989). For both specifications with macroeconomic level and variance in the MIDAS filter, 16 lags are taken to model $\log \tau_{t} . \theta_{l}$ and $\theta_{v}$ are rescaled by multiplication of $10^{-2}$ and $10^{-4}$ to make the macro level variables represented in percentage unit. The numbers in the parenthesis are robust $t$-stats computed with HAC standard errors.

\begin{tabular}{|c|c|c|c|c|c|c|c|}
\hline \multirow[b]{2}{*}{ Sample } & \multicolumn{7}{|c|}{ Level of IP } \\
\hline & $\mu$ & $\alpha$ & $\beta$ & $\theta_{l}$ & $\omega_{l, 1}$ & $\omega_{l, 2}$ & $m$ \\
\hline 1890-2004 & $\begin{array}{c}0.00056 \\
(13.57)\end{array}$ & $\begin{array}{c}0.09499 \\
(11.69)\end{array}$ & $\begin{array}{c}0.89481 \\
(105.34)\end{array}$ & $\begin{array}{c}-0.27666 \\
(-1.99)\end{array}$ & $\begin{array}{c}2.42355 \\
(2.57)\end{array}$ & $\begin{array}{c}2.90066 \\
(1.58)\end{array}$ & $\begin{array}{r}-8.97772 \\
(-55.99)\end{array}$ \\
\hline $1890-1919$ & $\begin{array}{c}0.00054 \\
(7.15)\end{array}$ & $\begin{array}{c}0.14157 \\
(9.41)\end{array}$ & $\begin{array}{c}0.81879 \\
(45.61)\end{array}$ & $\begin{array}{c}-0.09659 \\
(-2.05)\end{array}$ & $\begin{array}{c}40.18934 \\
(0.94)\end{array}$ & $\begin{array}{c}140.04966 \\
(0.87)\end{array}$ & $\begin{array}{c}-9.42615 \\
(-78.56)\end{array}$ \\
\hline 1920-1952 & $\begin{array}{c}0.00073 \\
(9.22)\end{array}$ & $\begin{array}{c}0.09488 \\
(9.53)\end{array}$ & $\begin{array}{c}0.89602 \\
(84.88)\end{array}$ & $\begin{array}{c}-0.18956 \\
(-1.90)\end{array}$ & $\begin{array}{c}2.70598 \\
(1.03)\end{array}$ & $\begin{array}{c}3.19719 \\
(1.33)\end{array}$ & $\begin{array}{c}-8.65862 \\
(-33.44)\end{array}$ \\
\hline 1953-2004 & $\begin{array}{c}0.00052 \\
(8.17)\end{array}$ & $\begin{array}{c}0.07719 \\
(6.98)\end{array}$ & $\begin{array}{c}0.91537 \\
(81.50)\end{array}$ & $\begin{array}{c}-0.97995 \\
(-2.61)\end{array}$ & $\begin{array}{c}4.71858 \\
(1.00)\end{array}$ & $\begin{array}{c}2.93907 \\
(0.91)\end{array}$ & $\begin{array}{c}-8.97020 \\
(-34.76)\end{array}$ \\
\hline 1953-1984 & $\begin{array}{c}0.00048 \\
(6.09)\end{array}$ & $\begin{array}{c}0.08116 \\
(7.76)\end{array}$ & $\begin{array}{c}0.90720 \\
(78.79)\end{array}$ & $\begin{array}{c}-0.91602 \\
(-2.43)\end{array}$ & $\begin{array}{c}5.64629 \\
(0.83)\end{array}$ & $\begin{array}{c}3.85090 \\
(0.88)\end{array}$ & $\begin{array}{r}-9.36597 \\
(-45.23)\end{array}$ \\
\hline \multirow[t]{2}{*}{$1985-2004$} & $\begin{array}{c}0.00067 \\
(5.57)\end{array}$ & $\begin{array}{c}0.08119 \\
(2.91)\end{array}$ & $\begin{array}{c}0.90727 \\
(30.40)\end{array}$ & $\begin{array}{c}-1.18704 \\
(-1.71)\end{array}$ & $\begin{array}{c}16.13726 \\
(0.41)\end{array}$ & $\begin{array}{c}2.81964 \\
(0.48)\end{array}$ & $\begin{array}{r}-8.70549 \\
(-22.74)\end{array}$ \\
\hline & \multicolumn{7}{|c|}{ Variance of IP } \\
\hline Sample & $\mu$ & $\alpha$ & $\beta$ & $\theta_{v}$ & $\omega_{v, 1}$ & $\omega_{v, 2}$ & $m$ \\
\hline 1890-2004 & $\begin{array}{c}0.00056 \\
(11.44)\end{array}$ & $\begin{array}{c}0.09694 \\
(14.44)\end{array}$ & $\begin{array}{c}0.89053 \\
(120.92)\end{array}$ & $\begin{array}{c}0.07487 \\
(6.04)\end{array}$ & $\begin{array}{c}2.60113 \\
(1.25)\end{array}$ & $\begin{array}{c}1.48199 \\
(2.70)\end{array}$ & $\begin{array}{c}-9.33932 \\
(-78.59)\end{array}$ \\
\hline $1890-1919$ & $\begin{array}{c}0.00054 \\
(7.57)\end{array}$ & $\begin{array}{c}0.13932 \\
(9.62)\end{array}$ & $\begin{array}{c}0.81980 \\
(45.86)\end{array}$ & $\begin{array}{c}0.02446 \\
(2.15)\end{array}$ & $\begin{array}{c}243.02613 \\
(93.86)\end{array}$ & $\begin{array}{c}299.99971 \\
(143.60)\end{array}$ & $\begin{array}{r}-9.54998 \\
(-73.31)\end{array}$ \\
\hline 1920-1952 & $\begin{array}{c}0.00073 \\
(8.39)\end{array}$ & $\begin{array}{c}0.09794 \\
(9.60)\end{array}$ & $\begin{array}{c}0.88783 \\
(80.70)\end{array}$ & $\begin{array}{c}0.06086 \\
(4.39)\end{array}$ & $\begin{array}{c}8.02994 \\
(1.56)\end{array}$ & $\begin{array}{c}2.52323 \\
(2.89)\end{array}$ & $\begin{array}{r}-9.20466 \\
(-40.88)\end{array}$ \\
\hline 1953-2004 & $\begin{array}{c}0.00051 \\
(7.58)\end{array}$ & $\begin{array}{c}0.07521 \\
(6.06)\end{array}$ & $\begin{array}{c}0.91845 \\
(72.43)\end{array}$ & $\begin{array}{c}0.05856 \\
(1.03)\end{array}$ & $\begin{array}{c}67.72180 \\
(0.92)\end{array}$ & $\begin{array}{c}13.80331 \\
(1.03)\end{array}$ & $\begin{array}{c}-9.23309 \\
(-35.47)\end{array}$ \\
\hline 1953-1984 & $\begin{array}{c}0.00047 \\
(6.19)\end{array}$ & $\begin{array}{c}0.07946 \\
(8.93)\end{array}$ & $\begin{array}{c}0.91062 \\
(90.93)\end{array}$ & $\begin{array}{c}0.31918 \\
(1.84)\end{array}$ & $\begin{array}{c}2.54411 \\
(1.11)\end{array}$ & $\begin{array}{c}2.07558 \\
(3.51)\end{array}$ & $\begin{array}{r}-9.81497 \\
(-51.99)\end{array}$ \\
\hline 1985-2004 & $\begin{array}{c}0.00066 \\
(5.59)\end{array}$ & $\begin{array}{c}0.07740 \\
(2.91)\end{array}$ & $\begin{array}{c}0.91338 \\
(33.16)\end{array}$ & $\begin{array}{c}1.23540 \\
(3.45)\end{array}$ & $\begin{array}{c}300.00000 \\
(1.89)\end{array}$ & $\begin{array}{c}30.09057 \\
(2.06)\end{array}$ & $\begin{array}{c}-9.10001 \\
(-24.96)\end{array}$ \\
\hline
\end{tabular}




\section{Table 6: Parameter Estimates of GARCH-MIDAS with Level and Variance Combined}

GARCH-MIDAS models with IP and PPI level/volatility series are fitted via QMLE. The specification appears in equation (14). Quarterly macroeconomic level variable is obtained by taking geometric mean of monthly rates. The corresponding variance is estimated from equation (19), a similar approach to Schwert (1989). For both macroeconomic level and variance in the MIDAS filter, $16 \operatorname{lags}$ are taken to model $\log \tau_{t}$. $\theta_{l}$ and $\theta_{v}$ are rescaled by multiplication of $10^{-2}$ and $10^{-4}$ to make the macro level variables represented in percentage unit. The numbers in the parenthesis are robust $t$-stats computed with HAC standard errors.

\begin{tabular}{|c|c|c|c|c|c|c|c|c|c|c|}
\hline Sample & $\mu$ & $\alpha$ & $\beta$ & $\theta_{l}$ & $\omega_{l, 1}$ & $\omega_{l, 2}$ & $\theta_{v}$ & $\omega_{v, 1}$ & $\omega_{v, 2}$ & $m$ \\
\hline & \multicolumn{10}{|c|}{ PPI } \\
\hline 1890-2004 & $\begin{array}{c}0.00056 \\
(38.71)\end{array}$ & $\begin{array}{c}0.09577 \\
(35.17)\end{array}$ & $\begin{array}{l}0.89342 \\
(109.71)\end{array}$ & $\begin{array}{c}0.26545 \\
(1.84)\end{array}$ & $\begin{array}{c}16.31711 \\
(0.73)\end{array}$ & $\begin{array}{c}3.52783 \\
(0.97)\end{array}$ & $\begin{array}{c}0.06544 \\
(0.86)\end{array}$ & $\begin{array}{c}7.64032 \\
(0.37)\end{array}$ & $\begin{array}{c}2.59355 \\
(0.75)\end{array}$ & $\begin{array}{c}-9.20210 \\
(-42.49)\end{array}$ \\
\hline 1890-1919 & $\begin{array}{c}0.00053 \\
(0.23)\end{array}$ & $\begin{array}{c}0.14380 \\
(0.32)\end{array}$ & $\begin{array}{c}0.80822 \\
(1.21)\end{array}$ & $\begin{array}{c}0.18369 \\
(0.02)\end{array}$ & $\begin{array}{c}2.99299 \\
(0.00)\end{array}$ & $\begin{array}{c}35.93817 \\
(0.00)\end{array}$ & $\begin{array}{c}0.21308 \\
(2.16)\end{array}$ & $\begin{array}{c}5.35999 \\
(0.00)\end{array}$ & $\begin{array}{c}1.00001 \\
(0.00)\end{array}$ & $\begin{array}{c}-9.79149 \\
(-10.93)\end{array}$ \\
\hline 1920-1952 & $\begin{array}{c}0.00073 \\
(28.87)\end{array}$ & $\begin{array}{c}0.09353 \\
(16.06)\end{array}$ & $\begin{array}{c}0.89787 \\
(77.44)\end{array}$ & $\begin{array}{c}0.24101 \\
(1.51)\end{array}$ & $\begin{array}{c}23.80903 \\
(1.16)\end{array}$ & $\begin{array}{c}3.46200 \\
(1.24)\end{array}$ & $\begin{array}{c}0.03687 \\
(0.91)\end{array}$ & $\begin{array}{c}300.00000 \\
(0.95)\end{array}$ & $\begin{array}{c}51.89784 \\
(0.96)\end{array}$ & $\begin{array}{c}-8.80583 \\
(-38.64)\end{array}$ \\
\hline 1953-2004 & $\begin{array}{l}0.00051 \\
(25.69)\end{array}$ & $\begin{array}{l}0.07741 \\
(12.28)\end{array}$ & $\begin{array}{c}0.91464 \\
(62.59)\end{array}$ & $\begin{array}{c}0.83498 \\
(0.73)\end{array}$ & $\begin{array}{c}22.56342 \\
(0.15)\end{array}$ & $\begin{array}{c}6.54459 \\
(0.25)\end{array}$ & $\begin{array}{l}0.10025 \\
(105.05)\end{array}$ & $\begin{array}{c}87.24949 \\
(0.29)\end{array}$ & $\begin{array}{c}14.37031 \\
(0.29)\end{array}$ & $\begin{array}{c}-9.47324 \\
(-18.06)\end{array}$ \\
\hline 1953-1984 & $\begin{array}{c}0.00047 \\
(59.40)\end{array}$ & $\begin{array}{c}0.08029 \\
(20.34)\end{array}$ & $\begin{array}{c}0.90318 \\
(39.42)\end{array}$ & $\begin{array}{c}0.42313 \\
(1.87)\end{array}$ & $\begin{array}{c}300.00000 \\
(0.77)\end{array}$ & $\begin{array}{c}149.99514 \\
(0.81)\end{array}$ & $\begin{array}{c}0.99909 \\
(13.98)\end{array}$ & $\begin{array}{c}28.59527 \\
(1.85)\end{array}$ & $\begin{array}{c}6.90855 \\
(1.72)\end{array}$ & $\begin{array}{c}-9.99398 \\
(-39.95)\end{array}$ \\
\hline \multirow[t]{2}{*}{ 1985-2004 } & $\begin{array}{c}0.00065 \\
(44.44)\end{array}$ & $\begin{array}{c}0.07728 \\
(7.66)\end{array}$ & $\begin{array}{c}0.91260 \\
(39.51)\end{array}$ & $\begin{array}{c}0.83396 \\
(2.56)\end{array}$ & $\begin{array}{c}187.67441 \\
(1.90)\end{array}$ & $\begin{array}{c}300.00000 \\
(1.89)\end{array}$ & $\begin{array}{c}0.10540 \\
(3.36)\end{array}$ & $\begin{array}{c}300.00000 \\
(0.21)\end{array}$ & $\begin{array}{c}105.04887 \\
(0.20)\end{array}$ & $\begin{array}{c}-9.08392 \\
(-29.75)\end{array}$ \\
\hline & \multicolumn{10}{|c|}{ IP } \\
\hline 1890-2004 & $\begin{array}{l}0.00057 \\
(53.84)\end{array}$ & $\begin{array}{c}0.09713 \\
(26.77)\end{array}$ & $\begin{array}{l}0.88973 \\
(104.64)\end{array}$ & $\begin{array}{c}-0.26152 \\
(-0.84)\end{array}$ & $\begin{array}{c}2.42752 \\
(0.92)\end{array}$ & $\begin{array}{c}2.02052 \\
(0.48)\end{array}$ & $\begin{array}{c}0.07588 \\
(3.10)\end{array}$ & $\begin{array}{c}1.37742 \\
(1.44)\end{array}$ & $\begin{array}{c}1.17955 \\
(1.67)\end{array}$ & $\begin{array}{r}-9.27531 \\
(-64.09)\end{array}$ \\
\hline 1890-1919 & $\begin{array}{c}0.00054 \\
(36.82)\end{array}$ & $\begin{array}{c}0.13974 \\
(35.91)\end{array}$ & $\begin{array}{c}0.81747 \\
(49.03)\end{array}$ & $\begin{array}{c}-0.06005 \\
(-1.92)\end{array}$ & $\begin{array}{c}300.00000 \\
(1.65)\end{array}$ & $\begin{array}{c}91.48020 \\
(1.73)\end{array}$ & $\begin{array}{c}0.02705 \\
(1.41)\end{array}$ & $\begin{array}{c}187.06963 \\
(0.11)\end{array}$ & $\begin{array}{c}230.57839 \\
(0.10)\end{array}$ & $\begin{array}{l}-9.55180 \\
(-149.28)\end{array}$ \\
\hline 1920-1952 & $\begin{array}{c}0.00073 \\
(35.50)\end{array}$ & $\begin{array}{c}0.09769 \\
(38.37)\end{array}$ & $\begin{array}{c}0.88804 \\
(92.17)\end{array}$ & $\begin{array}{c}-0.05322 \\
(-1.45)\end{array}$ & $\begin{array}{c}300.00000 \\
(1.15)\end{array}$ & $\begin{array}{c}192.31363 \\
(1.20)\end{array}$ & $\begin{array}{c}0.07561 \\
(2.96)\end{array}$ & $\begin{array}{c}1.33973 \\
(0.82)\end{array}$ & $\begin{array}{c}1.00000 \\
(1.34)\end{array}$ & $\begin{array}{c}-9.28313 \\
(-36.78)\end{array}$ \\
\hline 1953-2004 & $\begin{array}{c}0.00053 \\
(19.47)\end{array}$ & $\begin{array}{c}0.07808 \\
(13.38)\end{array}$ & $\begin{array}{c}0.91397 \\
(70.04)\end{array}$ & $\begin{array}{c}-1.04182 \\
(-1.77)\end{array}$ & $\begin{array}{c}4.75446 \\
(1.65)\end{array}$ & $\begin{array}{c}2.98089 \\
(1.25)\end{array}$ & $\begin{array}{c}0.11639 \\
(1.73)\end{array}$ & $\begin{array}{c}112.79673 \\
(2.98)\end{array}$ & $\begin{array}{c}300.00000 \\
(2.65)\end{array}$ & $\begin{array}{c}-9.04673 \\
(-26.05)\end{array}$ \\
\hline 1953-1984 & $\begin{array}{c}0.00050 \\
(36.84)\end{array}$ & $\begin{array}{c}0.08415 \\
(31.54)\end{array}$ & $\begin{array}{c}0.90157 \\
(96.57)\end{array}$ & $\begin{array}{c}-1.02798 \\
(-1.94)\end{array}$ & $\begin{array}{c}5.20349 \\
(1.47)\end{array}$ & $\begin{array}{c}3.56877 \\
(1.37)\end{array}$ & $\begin{array}{c}0.15256 \\
(2.40)\end{array}$ & $\begin{array}{c}111.58383 \\
(0.79)\end{array}$ & $\begin{array}{c}300.00000 \\
(0.77)\end{array}$ & $\begin{array}{c}-9.50151 \\
(-57.46)\end{array}$ \\
\hline 1985-2004 & $\begin{array}{c}0.00067 \\
(15.98)\end{array}$ & $\begin{array}{c}0.07476 \\
(9.37)\end{array}$ & $\begin{array}{c}0.91919 \\
(46.79)\end{array}$ & $\begin{array}{c}-0.50259 \\
(-0.90)\end{array}$ & $\begin{array}{c}300.00000 \\
(2.41)\end{array}$ & $\begin{array}{c}195.28726 \\
(2.68)\end{array}$ & $\begin{array}{l}1.49983 \\
(69.77)\end{array}$ & $\begin{array}{c}221.26956 \\
(4.61)\end{array}$ & $\begin{array}{c}22.98366 \\
(5.54)\end{array}$ & $\begin{array}{c}-8.83420 \\
(-9.62)\end{array}$ \\
\hline
\end{tabular}




\section{Table 7: Parameter Estimates of Two-sided GARCH-MIDAS with PPI and IP}

GARCH-MIDAS models with PPI or IP series are fitted using QMLE. The sample period marked with * is a sample period excluding 1987 crash; the stock return series and macroeconomic series corresponding to second half of 1987 is excluded from the sample. The specification appears in equation (15). Quarterly macroeconomic level variable is obtained by taking geometric mean of monthly rates. The corresponding variance is estimated from equation (19), a similar approach to Schwert (1989). For both macroeconomic level and variance in the MIDAS filter, 16 lags and 16 leads are taken to model $\log \tau_{t}$. $\theta_{l}$ and $\theta_{v}$ are rescaled by multiplication of $10^{-2}$ and $10^{-4}$ to make the macro level variables represented in percentage unit. The numbers in the parenthesis are robust $t$-stats computed with HAC standard errors.

\begin{tabular}{|c|c|c|c|c|c|c|c|c|c|c|c|c|}
\hline & $\mu$ & $\alpha$ & $\beta$ & $\theta_{l}^{b}$ & $\theta_{l}^{f}$ & $\theta_{v}^{b}$ & $\theta_{v}^{f}$ & $\omega_{1}$ & $\omega_{2}$ & $\omega_{3}$ & $\omega_{4}$ & $m$ \\
\hline & \multicolumn{12}{|c|}{ PPI series } \\
\hline 1890-2004 & $\begin{array}{l}0.00057 \\
(105.91)\end{array}$ & $\begin{array}{c}0.09678 \\
(55.15)\end{array}$ & $\begin{array}{l}0.89169 \\
(145.00)\end{array}$ & $\begin{array}{c}0.28341 \\
(1.45)\end{array}$ & $\begin{array}{c}0.29523 \\
(0.82)\end{array}$ & $\begin{array}{c}0.08601 \\
(0.81)\end{array}$ & $\begin{array}{c}0.18473 \\
(0.81)\end{array}$ & $\begin{array}{c}20.26192 \\
(0.66)\end{array}$ & $\begin{array}{c}26.08244 \\
(0.62)\end{array}$ & $\begin{array}{c}8.45295 \\
(0.65)\end{array}$ & $\begin{array}{c}10.34749 \\
(0.75)\end{array}$ & $\begin{array}{c}-9.27780 \\
(-54.69)\end{array}$ \\
\hline 1890-1919 & $\begin{array}{c}0.00053 \\
(35.24)\end{array}$ & $\begin{array}{c}0.14350 \\
(53.01)\end{array}$ & $\begin{array}{c}0.80576 \\
(47.06)\end{array}$ & $\begin{array}{c}0.28414 \\
(2.19)\end{array}$ & $\begin{array}{c}0.90884 \\
(0.25)\end{array}$ & $\begin{array}{c}0.21854 \\
(1.92)\end{array}$ & $\begin{array}{c}0.00151 \\
(1.65)\end{array}$ & $\begin{array}{c}52.39654 \\
(1.10)\end{array}$ & $\begin{array}{c}71.92129 \\
(1.03)\end{array}$ & $\begin{array}{c}3.03391 \\
(0.54)\end{array}$ & $\begin{array}{c}40.61308 \\
(0.39)\end{array}$ & $\begin{array}{c}-9.83587 \\
(-63.55)\end{array}$ \\
\hline 1920-1952 & $\begin{array}{c}0.00073 \\
(35.76)\end{array}$ & $\begin{array}{c}0.09396 \\
(22.55)\end{array}$ & $\begin{array}{c}0.89822 \\
(68.70)\end{array}$ & $\begin{array}{c}1.09287 \\
(0.53)\end{array}$ & $\begin{array}{c}0.35375 \\
(0.56)\end{array}$ & $\begin{array}{c}0.05589 \\
(0.62)\end{array}$ & $\begin{array}{c}0.15051 \\
(0.79)\end{array}$ & $\begin{array}{c}17.39842 \\
(0.83)\end{array}$ & $\begin{array}{c}13.23109 \\
(0.64)\end{array}$ & $\begin{array}{c}58.25269 \\
(0.77)\end{array}$ & $\begin{array}{c}63.90278 \\
(0.66)\end{array}$ & $\begin{array}{c}-8.81556 \\
(-16.61)\end{array}$ \\
\hline $1953-2004$ & $\begin{array}{c}0.00053 \\
(21.71)\end{array}$ & $\begin{array}{c}0.07814 \\
(35.23)\end{array}$ & $\begin{array}{c}0.91273 \\
(83.56)\end{array}$ & $\begin{array}{c}0.78515 \\
(1.54)\end{array}$ & $\begin{array}{c}319.05936 \\
(1.94)\end{array}$ & $\begin{array}{c}0.36701 \\
(1.93)\end{array}$ & $\begin{array}{c}0.26801 \\
(1.94)\end{array}$ & $\begin{array}{c}41.07113 \\
(2.51)\end{array}$ & $\begin{array}{c}76.16412 \\
(3.41)\end{array}$ & $\begin{array}{c}16.13123 \\
(3.47)\end{array}$ & $\begin{array}{c}300.00000 \\
(3.27)\end{array}$ & $\begin{array}{c}-9.63502 \\
(-28.50)\end{array}$ \\
\hline 1953-1984 & $\begin{array}{c}0.00047 \\
(29.43)\end{array}$ & $\begin{array}{c}0.08185 \\
(33.26)\end{array}$ & $\begin{array}{c}0.90173 \\
(53.70)\end{array}$ & $\begin{array}{c}1.05254 \\
(1.93)\end{array}$ & $\begin{array}{c}2918.61284 \\
(0.81)\end{array}$ & $\begin{array}{c}-0.51883 \\
(-0.80)\end{array}$ & $\begin{array}{c}1.15017 \\
(0.81)\end{array}$ & $\begin{array}{c}23.30470 \\
(0.88)\end{array}$ & $\begin{array}{c}55.79583 \\
(1.42)\end{array}$ & $\begin{array}{c}86.09265 \\
(1.42)\end{array}$ & $\begin{array}{c}300.00000 \\
(1.49)\end{array}$ & $\begin{array}{c}-9.97948 \\
(-36.18)\end{array}$ \\
\hline 1985-2004 & $\begin{array}{c}0.00074 \\
(44.20)\end{array}$ & $\begin{array}{c}0.09061 \\
(16.30)\end{array}$ & $\begin{array}{c}0.88136 \\
(28.03)\end{array}$ & $\begin{array}{c}-0.54966 \\
(-1.90)\end{array}$ & $\begin{array}{c}21.78506 \\
(1.81)\end{array}$ & $\begin{array}{c}11.45776 \\
(2.86)\end{array}$ & $\begin{array}{c}3.70936 \\
(1.90)\end{array}$ & $\begin{array}{c}18.61113 \\
(3.33)\end{array}$ & $\begin{array}{c}300.00000 \\
(3.85)\end{array}$ & $\begin{array}{c}2.36975 \\
(2.24)\end{array}$ & $\begin{array}{c}1.73479 \\
(1.73)\end{array}$ & $\begin{array}{c}-10.46234 \\
(-24.50)\end{array}$ \\
\hline \multirow[t]{2}{*}{$1985-2004^{*}$} & $\begin{array}{c}0.00062 \\
(6.89)\end{array}$ & $\begin{array}{c}0.03513 \\
(3.63)\end{array}$ & $\begin{array}{c}0.96242 \\
(36.03)\end{array}$ & $\begin{array}{c}11.27455 \\
(0.30)\end{array}$ & $\begin{array}{c}13.41385 \\
(0.27)\end{array}$ & $\begin{array}{c}0.71945 \\
(0.71)\end{array}$ & $\begin{array}{c}-0.00476 \\
(-0.37)\end{array}$ & $\begin{array}{c}1.93444 \\
(1.45)\end{array}$ & $\begin{array}{c}2.03338 \\
(0.75)\end{array}$ & $\begin{array}{c}37.73751 \\
(0.11)\end{array}$ & $\begin{array}{c}300.00000 \\
(0.10)\end{array}$ & $\begin{array}{c}-10.82070 \\
(-3.66)\end{array}$ \\
\hline & \multicolumn{12}{|c|}{ IP series } \\
\hline $1890-2004$ & $\begin{array}{c}0.00058 \\
(82.24)\end{array}$ & $\begin{array}{c}0.09901 \\
(38.06)\end{array}$ & $\begin{array}{c}0.88201 \\
(80.23)\end{array}$ & $\begin{array}{c}-0.86988 \\
(-0.84)\end{array}$ & $\begin{array}{c}-0.92877 \\
(-1.43)\end{array}$ & $\begin{array}{c}0.10266 \\
(1.07)\end{array}$ & $\begin{array}{c}0.18593 \\
(0.54)\end{array}$ & $\begin{array}{c}1.83330 \\
(1.55)\end{array}$ & $\begin{array}{c}2.54428 \\
(1.54)\end{array}$ & $\begin{array}{c}2.51452 \\
(0.24)\end{array}$ & $\begin{array}{c}3.16714 \\
(0.55)\end{array}$ & $\begin{array}{c}-9.35205 \\
(-28.29)\end{array}$ \\
\hline 1890-1919 & $\begin{array}{c}0.00054 \\
(47.59)\end{array}$ & $\begin{array}{c}0.14503 \\
(44.15)\end{array}$ & $\begin{array}{c}0.80089 \\
(32.73)\end{array}$ & $\begin{array}{c}-0.12499 \\
(-2.00)\end{array}$ & $\begin{array}{c}1.50459 \\
(0.69)\end{array}$ & $\begin{array}{c}0.09650 \\
(2.06)\end{array}$ & $\begin{array}{c}0.13656 \\
(1.29)\end{array}$ & $\begin{array}{c}31.10268 \\
(1.17)\end{array}$ & $\begin{array}{c}226.78195 \\
(1.10)\end{array}$ & $\begin{array}{c}28.67380 \\
(0.88)\end{array}$ & $\begin{array}{c}27.38901 \\
(1.03)\end{array}$ & $\begin{array}{c}-9.80616 \\
(-66.68)\end{array}$ \\
\hline 1920-1952 & $\begin{array}{l}0.00074 \\
(124.61)\end{array}$ & $\begin{array}{c}0.10004 \\
(46.48)\end{array}$ & $\begin{array}{c}0.86286 \\
(67.36)\end{array}$ & $\begin{array}{c}-0.42589 \\
(-3.06)\end{array}$ & $\begin{array}{c}0.30435 \\
(0.79)\end{array}$ & $\begin{array}{c}0.14860 \\
(2.65)\end{array}$ & $\begin{array}{c}0.15721 \\
(5.13)\end{array}$ & $\begin{array}{c}1.71286 \\
(3.26)\end{array}$ & $\begin{array}{c}1.81926 \\
(1.44)\end{array}$ & $\begin{array}{c}4.93039 \\
(2.88)\end{array}$ & $\begin{array}{c}3.39250 \\
(3.25)\end{array}$ & $\begin{array}{c}-9.88961 \\
(-65.37)\end{array}$ \\
\hline $1953-2004$ & $\begin{array}{c}0.00055 \\
(10.27)\end{array}$ & $\begin{array}{c}0.08552 \\
(5.79)\end{array}$ & $\begin{array}{c}0.89258 \\
(74.08)\end{array}$ & $\begin{array}{c}-3.42508 \\
(-0.41)\end{array}$ & $\begin{array}{c}-4.10994 \\
(-0.15)\end{array}$ & $\begin{array}{c}-0.01433 \\
(-0.14)\end{array}$ & $\begin{array}{c}-0.03582 \\
(-0.16)\end{array}$ & $\begin{array}{c}2.98868 \\
(0.40)\end{array}$ & $\begin{array}{c}2.79418 \\
(1.43)\end{array}$ & $\begin{array}{c}211.43088 \\
(0.16)\end{array}$ & $\begin{array}{c}1.00084 \\
(0.00)\end{array}$ & $\begin{array}{c}-8.46612 \\
(-8.57)\end{array}$ \\
\hline 1953-1984 & $\begin{array}{c}0.00053 \\
(36.70)\end{array}$ & $\begin{array}{c}0.09247 \\
(15.41)\end{array}$ & $\begin{array}{c}0.86958 \\
(43.14)\end{array}$ & $\begin{array}{c}-3.36394 \\
(-4.42)\end{array}$ & $\begin{array}{c}-4.21650 \\
(-5.42)\end{array}$ & $\begin{array}{c}0.17340 \\
(1.18)\end{array}$ & $\begin{array}{c}0.00009 \\
(2.78)\end{array}$ & $\begin{array}{c}3.00846 \\
(5.07)\end{array}$ & $\begin{array}{c}3.22511 \\
(4.09)\end{array}$ & $\begin{array}{c}51.63566 \\
(0.29)\end{array}$ & $\begin{array}{c}300.00000 \\
(0.28)\end{array}$ & $\begin{array}{c}-8.85431 \\
(-46.19)\end{array}$ \\
\hline $1985-2004$ & $\begin{array}{c}0.00073 \\
(76.34)\end{array}$ & $\begin{array}{c}0.09043 \\
(37.86)\end{array}$ & $\begin{array}{c}0.85325 \\
(27.65)\end{array}$ & $\begin{array}{c}-17.69083 \\
(-1.27)\end{array}$ & $\begin{array}{c}-3.14898 \\
(-6.29)\end{array}$ & $\begin{array}{c}0.00277 \\
(1.15)\end{array}$ & $\begin{array}{c}0.00151 \\
(1.22)\end{array}$ & $\begin{array}{c}5.80172 \\
(2.48)\end{array}$ & $\begin{array}{c}1.75117 \\
(3.42)\end{array}$ & $\begin{array}{c}12.96889 \\
(4.93)\end{array}$ & $\begin{array}{c}10.91845 \\
(11.41)\end{array}$ & $\begin{array}{c}-8.37420 \\
(-41.20)\end{array}$ \\
\hline $1985-2004^{*}$ & $\begin{array}{c}0.00066 \\
(23.58)\end{array}$ & $\begin{array}{c}0.04611 \\
(8.15)\end{array}$ & $\begin{array}{c}0.92404 \\
(26.82)\end{array}$ & $\begin{array}{c}-7.95350 \\
(-1.39)\end{array}$ & $\begin{array}{c}-3.10168 \\
(-4.42)\end{array}$ & $\begin{array}{c}0.00192 \\
(1.14)\end{array}$ & $\begin{array}{c}0.00085 \\
(1.27)\end{array}$ & $\begin{array}{c}5.38666 \\
(2.06)\end{array}$ & $\begin{array}{c}1.95158 \\
(3.23)\end{array}$ & $\begin{array}{c}12.93163 \\
(4.97)\end{array}$ & $\begin{array}{c}10.07683 \\
(15.26)\end{array}$ & $\begin{array}{c}-8.61166 \\
(-36.05)\end{array}$ \\
\hline
\end{tabular}




\section{Table 8: Parameter Estimates of Spline-GARCH}

Spline-GARCH-MIDAS models are fitted via QMLE. The specification appears in equation (17). For a given sample choice, the number of knots is selected via the BIC. For empirical implementation, we normalized $t$ in the equation (17) by dividing it with the total number of days in the sample. This makes our spline parameters typically bigger than those shown in Engle and Rangel (2007). The numbers in the parenthesis are robust $t$-stats computed with HAC standard errors.

\begin{tabular}{|c|c|c|c|c|c|c|c|c|c|c|}
\hline & $\mu$ & $\alpha$ & $\beta$ & $c$ & $\omega_{0}$ & & & & & \\
\hline $1890-2004$ & $\begin{array}{c}0.00058 \\
(15.87)\end{array}$ & $\begin{array}{c}0.10153 \\
(28.05)\end{array}$ & $\begin{array}{c}0.87899 \\
(181.36)\end{array}$ & $\begin{array}{c}0.00006 \\
(43.40)\end{array}$ & $\begin{array}{c}11.48195 \\
(104.22)\end{array}$ & & & & & \\
\hline $1890-1919$ & $\begin{array}{c}0.00053 \\
(7.66)\end{array}$ & $\begin{array}{c}0.14219 \\
(17.02)\end{array}$ & $\begin{array}{c}0.80760 \\
(61.86)\end{array}$ & $\begin{array}{c}0.00005 \\
(78.87)\end{array}$ & $\begin{array}{c}4.77284 \\
(60.31)\end{array}$ & & & & & \\
\hline $1920-1952$ & $\begin{array}{c}0.00076 \\
(9.22)\end{array}$ & $\begin{array}{c}0.09899 \\
(30.50)\end{array}$ & $\begin{array}{l}0.85998 \\
(115.91)\end{array}$ & $\begin{array}{l}0.00010 \\
(58.14)\end{array}$ & $\begin{array}{c}-0.62802 \\
(-0.93)\end{array}$ & & & & & \\
\hline $1953-2004$ & $\begin{array}{c}0.00055 \\
(9.24)\end{array}$ & $\begin{array}{c}0.08837 \\
(11.48)\end{array}$ & $\begin{array}{c}0.88075 \\
(99.97)\end{array}$ & $\begin{array}{c}0.00005 \\
(64.46)\end{array}$ & $\begin{array}{c}12.81664 \\
(5.29)\end{array}$ & & & & & \\
\hline $1953-1984$ & $\begin{array}{c}0.00051 \\
(7.37)\end{array}$ & $\begin{array}{c}0.09079 \\
(13.01)\end{array}$ & $\begin{array}{c}0.87796 \\
(88.93)\end{array}$ & $\begin{array}{c}0.00005 \\
(58.39)\end{array}$ & $\begin{array}{c}7.41979 \\
(35.95)\end{array}$ & & & & & \\
\hline \multirow[t]{2}{*}{$1985-2004$} & $\begin{array}{c}0.00068 \\
(6.75)\end{array}$ & $\begin{array}{c}0.08602 \\
(9.23)\end{array}$ & $\begin{array}{c}0.85996 \\
(50.59)\end{array}$ & $\begin{array}{c}0.00005 \\
(12.90)\end{array}$ & $\begin{array}{c}10.77975 \\
(31.79)\end{array}$ & & & & & \\
\hline & $\omega_{1}$ & $\omega_{2}$ & $\omega_{3}$ & $\omega_{4}$ & $\omega_{5}$ & $\omega_{6}$ & $\omega_{7}$ & $\omega_{8}$ & $\omega_{9}$ & $\mathrm{LLF} / \mathrm{BIC}$ \\
\hline $1890-2004$ & $\begin{array}{c}-62.71162 \\
(-20.99)\end{array}$ & $\begin{array}{c}81.22589 \\
(13.54)\end{array}$ & $\begin{array}{c}22.17711 \\
(18.95)\end{array}$ & $\begin{array}{c}-120.99219 \\
(-95.42)\end{array}$ & $\begin{array}{c}83.50810 \\
(24.73)\end{array}$ & $\begin{array}{c}88.70340 \\
(19.94)\end{array}$ & $\begin{array}{c}-171.12468 \\
(-34.82)\end{array}$ & $\begin{array}{c}131.14982 \\
(57.62)\end{array}$ & & $\begin{array}{c}106874.54 \\
-6.7474\end{array}$ \\
\hline 1890-1919 & $\begin{array}{r}-7.77547 \\
(-35.31)\end{array}$ & $\begin{array}{c}15.82539 \\
(72.32)\end{array}$ & & & & & & & & $\begin{array}{c}30599.92 \\
-6.9143\end{array}$ \\
\hline 1920-1952 & $\begin{array}{c}-41.85921 \\
(-36.09)\end{array}$ & $\begin{array}{c}137.65386 \\
(75.29)\end{array}$ & $\begin{array}{c}-71.97797 \\
(-53.07)\end{array}$ & $\begin{array}{c}-157.77405 \\
(-32.61)\end{array}$ & $\begin{array}{c}201.12332 \\
(31.84)\end{array}$ & $\begin{array}{c}-134.14541 \\
(-15.71)\end{array}$ & $\begin{array}{c}174.21059 \\
(20.05)\end{array}$ & $\begin{array}{c}-183.79679 \\
(-57.51)\end{array}$ & $\begin{array}{c}55.79314 \\
(13.77)\end{array}$ & $\begin{array}{c}31297.15 \\
-6.4219\end{array}$ \\
\hline $1953-2004$ & $\begin{array}{c}-99.23146 \\
(-21.57)\end{array}$ & $\begin{array}{c}194.77933 \\
(12.73)\end{array}$ & $\begin{array}{c}-136.05880 \\
(-45.71)\end{array}$ & $\begin{array}{c}68.47953 \\
(100.95)\end{array}$ & $\begin{array}{c}-88.75609 \\
(-22.44)\end{array}$ & $\begin{array}{c}145.82887 \\
(108.10)\end{array}$ & $\begin{array}{c}-200.23059 \\
(-9.50)\end{array}$ & & & $\begin{array}{c}45108.37 \\
-6.8833\end{array}$ \\
\hline $1953-1984$ & $\begin{array}{c}-33.15317 \\
(-35.87)\end{array}$ & $\begin{array}{c}66.11422 \\
(22.06)\end{array}$ & $\begin{array}{c}-47.94705 \\
(-54.92)\end{array}$ & $\begin{array}{c}22.67034 \\
(13.06)\end{array}$ & & & & & & $\begin{array}{c}28615.09 \\
-7.1055\end{array}$ \\
\hline $1985-2004$ & $\begin{array}{c}-28.70466 \\
(-17.17)\end{array}$ & $\begin{array}{c}57.60082 \\
(66.93)\end{array}$ & $\begin{array}{c}-71.44233 \\
(-9.43)\end{array}$ & & & & & & & $\begin{array}{c}16522.09 \\
-6.5338\end{array}$ \\
\hline
\end{tabular}




\section{Table 9: Structural Change Tests for GARCH-MIDAS models}

GARCH-MIDAS models with various specifications are fitted via QMLE over the full and sub-samples. To address the structural break question we compute a likelihood ratio statistic, comparing the log-likelihood function for the full sample with those of the sub-samples. In particular: $-2\left[L L F_{\text {full }}-\sum_{i=s u b-s a m p l e s} L L F_{i}\right]$ $\sim \chi^{2}(d f)$ where $d f$ is the number of parameters times one less than the number of sub-samples, which corresponds to the number of restrictions. The sub-samples come in two configurations (Test1) 1890-1919 / 1920-1952 / 1953-2004 and (Test2) 1890-1919 / 1920-1952 / 1953-1984 / 1985-2004.

\begin{tabular}{|c|c|c|c|c|c|c|c|c|}
\hline & Model & \# of Param. & df1 & Test 1 & $\mathrm{p}$-value & df2 & Test 2 & $\mathrm{p}$-value \\
\hline \multicolumn{2}{|c|}{ GM with Fixed Span RV } & 6 & 12 & 55.54 & $0.00 \%$ & 18 & 75.44 & $0.00 \%$ \\
\hline \multicolumn{2}{|c|}{ GM with Fixed Span RV (Log) } & 6 & 12 & 122.42 & $0.00 \%$ & 18 & 140.67 & $0.00 \%$ \\
\hline \multicolumn{9}{|c|}{ GM with Macro Series } \\
\hline \multirow[t]{3}{*}{ PPI } & Level & 7 & 14 & 130.25 & $0.00 \%$ & 21 & 179.25 & $0.00 \%$ \\
\hline & Variance & 7 & 14 & 140.56 & $0.00 \%$ & 21 & 207.90 & $0.00 \%$ \\
\hline & Level+Variance & 10 & 20 & 155.81 & $0.00 \%$ & 30 & 212.90 & $0.00 \%$ \\
\hline \multirow[t]{3}{*}{ IP } & Level & 7 & 14 & 134.61 & $0.00 \%$ & 21 & 179.44 & $0.00 \%$ \\
\hline & Variance & 7 & 14 & 101.37 & $0.00 \%$ & 21 & 161.40 & $0.00 \%$ \\
\hline & Level+Variance & 10 & 20 & 140.30 & $0.00 \%$ & 30 & 208.28 & $0.00 \%$ \\
\hline $\mathrm{PPI}+\mathrm{IP}$ & Level+Variance & 12 & 24 & 149.97 & $0.00 \%$ & 36 & 234.76 & $0.00 \%$ \\
\hline
\end{tabular}




\section{Table 10: Comparison of Forecasting Performance of Two Component Volatility Models using Full Sample Estimates}

Various GARCH-MIDAS models and Spline-GARCH model from Engle and Rangel (2007) are fitted over the full sample and the forecasting performance of these models over the sub-samples are compared. Note that all the models considered are two component volatility models. However, GARCH-MIDAS with fixed span RV and GARCH-MIDAS with macro level/vol fix the long run component for a certain period whereas others do not. For those with fixed component, the models are estimated separately for each forecasting horizon to match the fixing term with the forecasting horizon. Also, for these models, the number of lags used in MIDAS filter is determined such that the MIDAS regressors span past 4 years of data (e.g. 16 lags for quarterly RV). To be consistent with others, 'Qtr/4yr' GARCH-MIDAS with rolling window RV as described in Tables 2 and 3 are used. The parameters for the each model are estimated using the fullsample and the forecasts for next month/quarter/semester are computed assuming that today is the last day of a month/quarter/semester. The Mean Squared Errors (henceforth MSE) of the forecasts are calculated with respect to monthly, quarterly and half-year realized variance computed from daily stock return series. For the purpose of comparison, GARCH-MIDAS model with rolling window RV is chosen as a benchmark. Except for this case, all the other MSE's are presented as a ratio to the base MSE from the forecasts of GARCH-MIDAS with rolling window RV for the corresponding forecasting horizon and the sub-sample.

\begin{tabular}{|c|c|c|c|c|c|c|}
\hline \multirow{2}{*}{$\begin{array}{l}\text { Forecasting } \\
\text { Horizon }\end{array}$} & \multicolumn{6}{|c|}{ MSE Ratio - relative to GARCH-MIDAS with Rolling Window RV } \\
\hline & $1890-2004$ & 1890-1919 & $1920-1952$ & $1953-2004$ & $1953-1984$ & $1985-2004$ \\
\hline \multicolumn{7}{|c|}{ GARCH-MIDAS with Rolling Window RV } \\
\hline Month & 0.000014 & 0.000005 & 0.000027 & 0.000012 & 0.000001 & 0.000029 \\
\hline Quarter & 0.000078 & 0.000025 & 0.000183 & 0.000043 & 0.000008 & 0.000099 \\
\hline Semester & 0.000263 & 0.000063 & 0.000680 & 0.000111 & 0.000027 & 0.000246 \\
\hline \multicolumn{7}{|c|}{ GARCH-MIDAS with Fixed Span RV } \\
\hline Month & 1.91 & 1.21 & 1.71 & 2.37 & 1.29 & 2.45 \\
\hline Quarter & 0.99 & 1.37 & 0.94 & 1.03 & 1.14 & 1.01 \\
\hline Semester & 0.84 & 1.28 & 0.76 & 1.00 & 1.09 & 0.98 \\
\hline \multicolumn{7}{|c|}{ GARCH-MIDAS with Rolling Window RV (Log) } \\
\hline Month & 1.08 & 1.09 & 1.10 & 1.04 & 1.10 & 1.04 \\
\hline Quarter & 1.02 & 1.17 & 1.01 & 0.99 & 1.08 & 0.98 \\
\hline Semester & 0.97 & 1.03 & 0.96 & 0.98 & 1.04 & 0.96 \\
\hline \multicolumn{7}{|c|}{ GARCH-MIDAS with Fixed Span RV (Log) } \\
\hline Month & 1.40 & 1.15 & 1.37 & 1.49 & 1.11 & 1.52 \\
\hline Quarter & 1.16 & 1.34 & 1.20 & 1.01 & 1.11 & 0.99 \\
\hline Semester & 0.97 & 1.22 & 0.95 & 0.98 & 1.09 & 0.96 \\
\hline \multicolumn{7}{|c|}{ Spline-GARCH } \\
\hline Month & 1.05 & 1.10 & 1.08 & 1.01 & 1.07 & 1.00 \\
\hline Quarter & 1.06 & 1.29 & 1.07 & 0.97 & 1.09 & 0.95 \\
\hline Semester & 1.08 & 1.12 & 1.12 & 0.91 & 1.01 & 0.89 \\
\hline
\end{tabular}

Table continued on next page ... 


\begin{tabular}{lcccccc}
\hline \hline Forecasting & \multicolumn{7}{c}{ MSE Ratio } \\
Horizon & $1890-2004$ & $1890-1919$ & $1920-1952$ & $1953-2004$ & $1953-1984$ & $1985-2004$ \\
\hline \multirow{7}{*}{ GARCH-MIDAS with PPI level } \\
Month & 1.12 & 1.22 & 1.12 & 1.11 & 1.17 & 1.10 \\
Quarter & 1.09 & 1.88 & 1.02 & 1.01 & 1.36 & 0.97 \\
Semester & 1.08 & 1.90 & 1.04 & 0.97 & 1.38 & 0.90 \\
\hline \multicolumn{7}{c}{ GARCH-MIDAS with PPI variance } \\
Month & 1.12 & 1.24 & 1.12 & 1.10 & 1.17 & 1.10 \\
Quarter & 1.08 & 1.88 & 1.01 & 1.02 & 1.35 & 0.98 \\
Semester & 1.06 & 2.06 & 1.00 & 0.98 & 1.44 & 0.90 \\
\hline \multicolumn{7}{c}{ GARCH-MIDAS with PPI (level+variance) } \\
Month & 1.12 & 1.21 & 1.12 & 1.10 & 1.15 & 1.10 \\
Quarter & 1.09 & 1.85 & 1.02 & 1.01 & 1.32 & 0.97 \\
Semester & 1.09 & 1.94 & 1.05 & 0.97 & 1.34 & 0.91 \\
\hline \multicolumn{7}{c}{ GARCH-MIDAS with IP level } \\
Month & 1.12 & 1.22 & 1.11 & 1.12 & 1.18 & 1.11 \\
Quarter & 1.05 & 1.81 & 0.98 & 1.02 & 1.38 & 0.97 \\
Semester & 0.95 & 1.85 & 0.87 & 0.99 & 1.49 & 0.90 \\
\hline \multicolumn{7}{c}{ GARCH-MIDAS with IP variance } \\
Month & 1.13 & 1.26 & 1.12 & 1.11 & 1.18 & 1.10 \\
Quarter & 1.06 & 1.67 & 1.01 & 1.01 & 1.23 & 0.99 \\
Semester & 1.02 & 1.85 & 0.96 & 0.98 & 1.28 & 0.93 \\
\hline GARCH-MIDAS with IP (level+variance) \\
Month & 1.11 & 1.24 & 1.09 & 1.10 & 1.18 & 1.10 \\
Quarter & 1.06 & 1.54 & 1.03 & 1.01 & 1.20 & 0.98 \\
Semester & 0.92 & 1.85 & 0.82 & 0.98 & 1.23 & 0.93 \\
\hline \hline
\end{tabular}




\section{Table 11: Comparison of Forecasting Performance of Two Component Volatility Models for One Semester Horizon using Sub-sample Estimates}

Various GARCH-MIDAS models are fitted over each of sub-samples separately and the forecasting performance of these models over the sub-samples are compared. Note that all the models considered are two component volatility models. However, GARCH-MIDAS with fixed span RV and GARCH-MIDAS with macro level/vol fix the long run component for a certain period whereas others do not. For those with fixed component, the models are estimated separately for each forecasting horizon to match the fixing term with the forecasting horizon. Also, for these models, the number of lags used in MIDAS filter is determined such that the MIDAS regressors span past 4 years of data (e.g. 16 lags for quarterly RV). To be consistent with others, 'Qtr/4yr' GARCH-MIDAS with rolling window RV as described in Table 2 is used. The parameters for the each model are estimated using the sub-samples and the forecasts for next month/quarter/semester are computed assuming that today is the last day of a month/quarter/semester. The Mean Squared Errors (henceforth MSE) of the forecasts are calculated with respect to monthly, quarterly and half-year realized variance computed from daily stock return series. For the purpose of comparison, GARCH-MIDAS model with rolling window RV is chosen as a benchmark. Except for this case, all the other MSE's are presented as a ratio to the base MSE from the forecasts of GARCH-MIDAS with rolling window RV for the corresponding forecasting horizon and the sub-sample.

\begin{tabular}{lccccc}
\hline \hline & \multicolumn{5}{c}{ MSE Ratio for semi-annual forecast horizon } \\
GARCH-MIDAS with PPI level & $1890-1919$ & $1920-1952$ & $1953-2004$ & $1953-1984$ & $1985-2004$ \\
GARCH-MIDAS with PPI variance & 0.79 & 0.93 & 1.07 & 0.90 & 0.99 \\
GARCH-MIDAS with PPI (level+variance) & 0.73 & 0.86 & 0.98 & 0.80 & 0.86 \\
GARCH-MIDAS with IP level & 0.75 & 0.93 & 1.06 & 0.83 & 0.90 \\
GARCH-MIDAS with IP variance & 0.78 & 0.92 & 0.98 & 1.05 & 0.97 \\
GARCH-MIDAS with IP (level+variance) & 0.77 & 0.89 & 0.98 & 1.02 & 1.04 \\
\end{tabular}




\section{Table 12: Summary Table for Variance Ratios}

The first variance ratio is: $\operatorname{Var}\left(\log \left(\tau_{t}^{[M]}\right)\right) / \operatorname{Var}\left(\log \left(\tau_{t}^{[M]} g_{t}^{[M]}\right)\right)$, where $M$ refers to a specific model: GARCHMIDAS with rolling window RV, with fixed span RV, with Macro variables, and finally Spline-GARCH. Except for GARCH-MIDAS with rolling RV, each model has a second line which refers to a variance ratio normalized by $\operatorname{Var}\left(\log \left(\tau_{t}^{[g m-\operatorname{roll} R V]} g_{t}^{[g m-\operatorname{roll} R V]}\right)\right)$.

\begin{tabular}{|c|c|c|c|c|c|c|c|}
\hline & Model & 1890-2004 & 1890-1919 & $1920-1952$ & $1953-2004$ & 1953-1984 & 1985-2004 \\
\hline \multicolumn{2}{|c|}{ GM with Rolling Window RV } & 46.15 & 24.57 & 54.09 & 37.22 & 29.39 & 27.75 \\
\hline \multicolumn{2}{|c|}{ GM with Rolling Window RV (Log) } & 32.86 & 17.44 & 45.89 & 23.84 & 19.04 & 19.16 \\
\hline \multicolumn{2}{|c|}{ GM with Fixed Span RV } & 41.23 & 14.82 & 52.05 & 31.99 & 9.06 & 30.47 \\
\hline & & 41.02 & 14.60 & 51.23 & 31.57 & 8.94 & 30.29 \\
\hline \multirow{2}{*}{\multicolumn{2}{|c|}{ GM with Fixed Span RV (Log) }} & 32.37 & 11.20 & 45.35 & 25.99 & 8.74 & 21.99 \\
\hline & & 32.14 & 10.96 & 45.34 & 25.91 & 8.66 & 21.88 \\
\hline \multirow{2}{*}{\multicolumn{2}{|c|}{ Spline-GARCH }} & 25.22 & 12.87 & 53.67 & 54.81 & 54.55 & 59.37 \\
\hline & & 25.13 & 12.45 & 52.87 & 54.13 & 56.97 & 59.14 \\
\hline \multicolumn{8}{|c|}{ GM with Macro Series } \\
\hline \multirow{2}{*}{\multicolumn{2}{|c|}{ PPI Level }} & 5.82 & 6.89 & 5.96 & 17.11 & 35.10 & 10.16 \\
\hline & & 5.78 & 6.72 & 5.97 & 17.10 & 35.54 & 10.33 \\
\hline \multirow{2}{*}{\multicolumn{2}{|c|}{ Variance }} & 0.43 & 9.51 & 0.45 & 5.91 & 22.36 & 6.85 \\
\hline & & 0.42 & 9.26 & 0.45 & 5.77 & 22.19 & 7.14 \\
\hline \multirow{2}{*}{\multicolumn{2}{|c|}{ Level+Variance }} & 5.07 & 13.50 & 5.41 & 17.25 & 35.89 & 11.60 \\
\hline & & 5.03 & 13.30 & 5.41 & 17.20 & 36.23 & 11.65 \\
\hline \multirow{6}{*}{ IP } & Level & 2.76 & 4.12 & 2.44 & 11.32 & 17.04 & 16.31 \\
\hline & & 2.74 & 4.02 & 2.42 & 11.25 & 17.11 & 16.47 \\
\hline & Variance & 11.08 & 3.66 & 15.38 & 0.43 & 5.56 & 10.40 \\
\hline & & 11.02 & 3.54 & 15.26 & 0.42 & 5.51 & 10.67 \\
\hline & Level+Variance & 13.02 & 5.91 & 14.20 & 14.11 & 25.09 & 21.43 \\
\hline & & 12.93 & 5.72 & 14.05 & 14.07 & 25.45 & 23.63 \\
\hline
\end{tabular}




\section{Figure 1: Optimal Weighting Functions}

The figure shows the estimated optimal lag weights for variations of GARCH-MIDAS with fixed span RV over the full sample period. MIDAS lag year is the number of years spanned in MIDAS regression for $\tau$ and it determines the number of lagged RV's in MIDAS filter. For example, GARCH-MIDAS with monthly fixed span RV and 3 MIDAS lag years uses 36 lagged monthly RV's in MIDAS regression for $\tau$. Three choices of regressors (monthly/quarterly/biannual RV) are considered and three choices of number of lags (3, 4 and 5 MIDAS lag years) are considered. The horizontal axis of the figure is lag period in "months." Hence, weights for GARCH-MIDAS with quarterly fixed span RV show shapes of step functions. Weights for GARCH-MIDAS with quarterly fixed span RV shown in the figure are constant for 3 months. The biannual case can be understood in the similar sense.
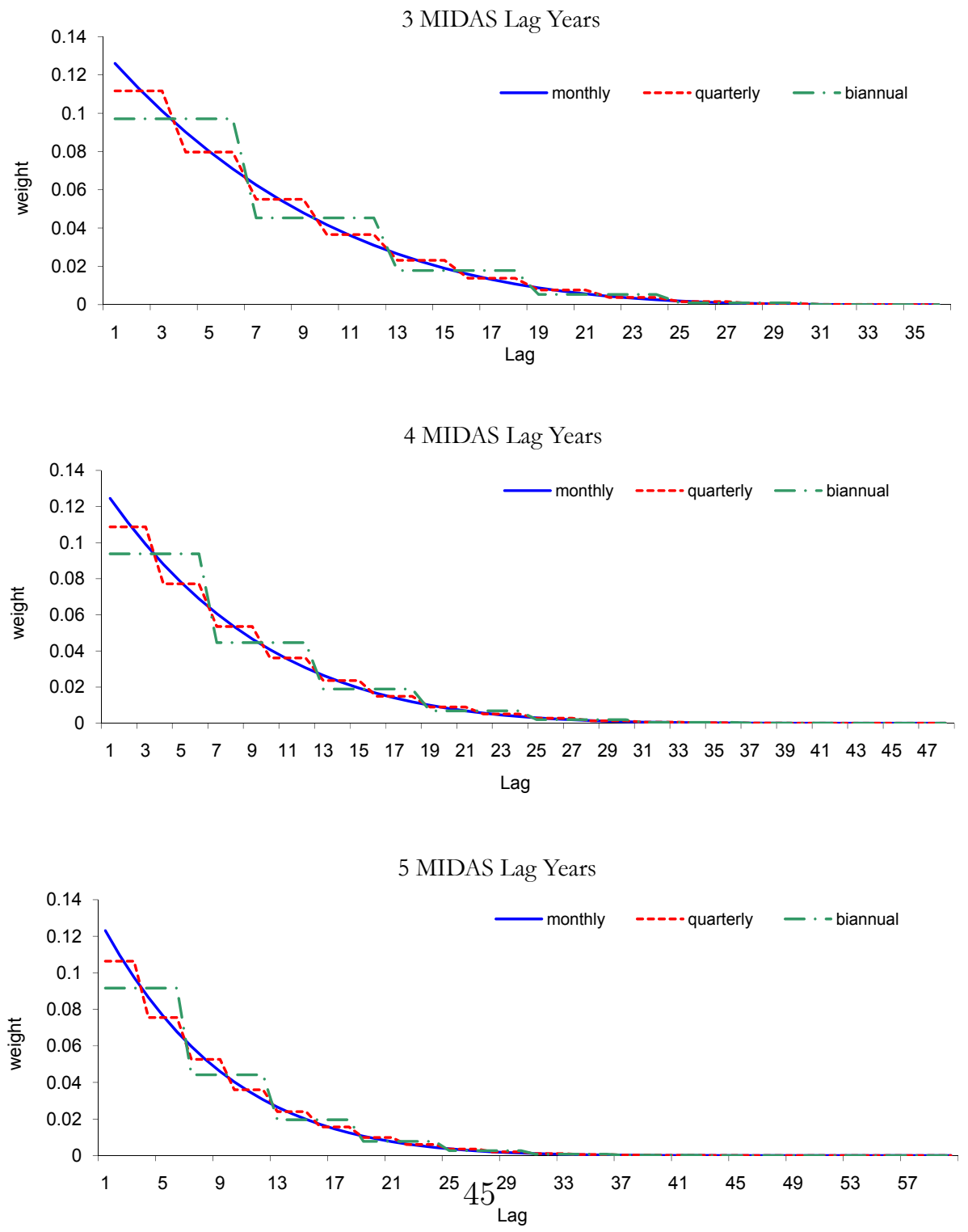


\section{Figure 2: GARCH-MIDAS with Fixed Span RV, 1890-2004}

The first panel shows the estimated conditional volatility and its long run component of GARCH-MIDAS model with quarterly fixed RV and 4 MIDAS lag years of RV's (or 16 lagged quarterly RV's) in the MIDAS filter. They are all shown in standard deviation and annualized scale. The estimated parameters are shown in the first row of Table 2. In the second panel, these conditional variance and long run component are summed over quarters to show quarterly aggregated conditional variance and quarterly aggregated long run component with quarterly RV's for comparison. As in the first panel, these are shown in standard deviation and annualized scale.
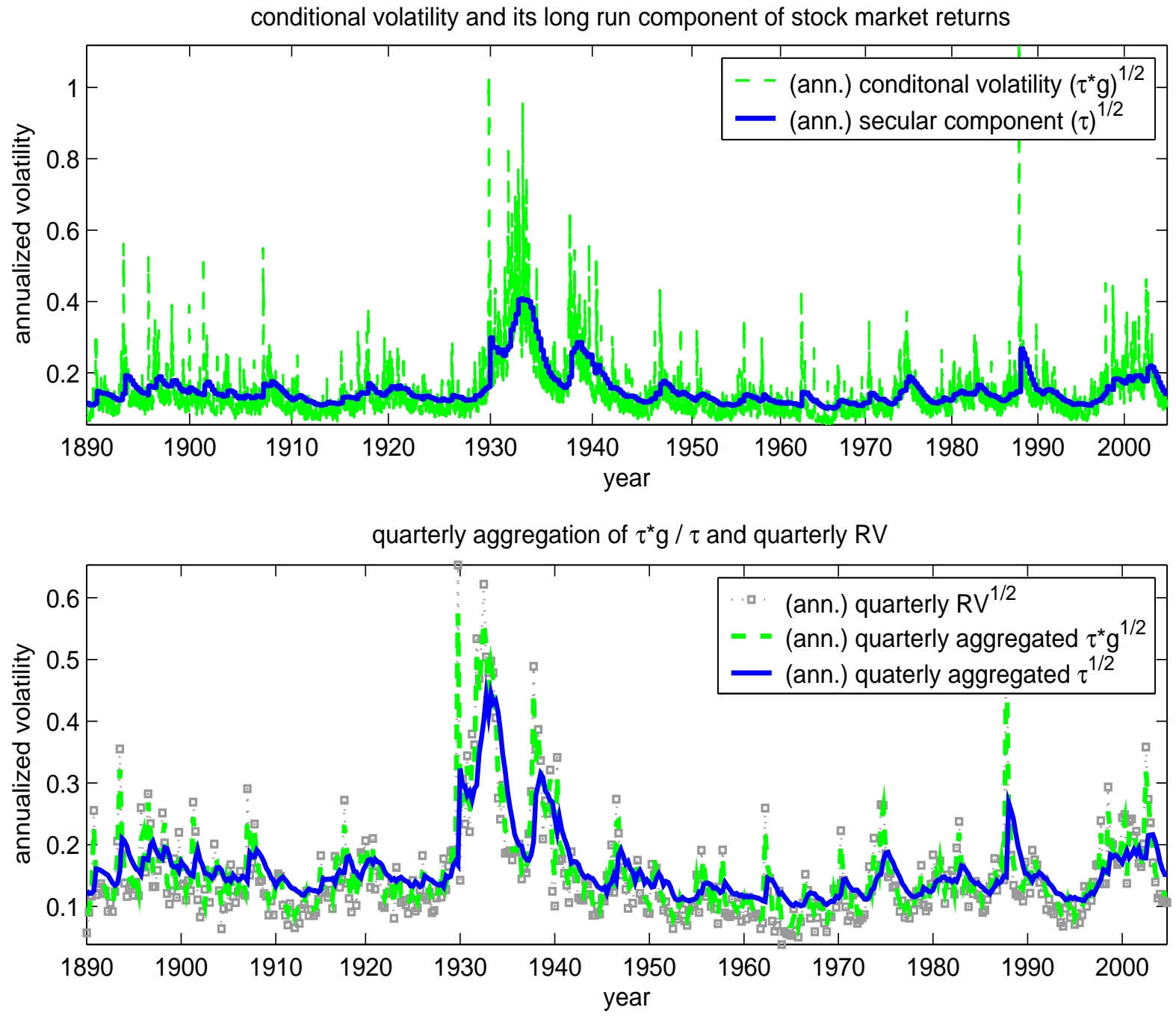
Figure 3: GARCH-MIDAS with Rolling Window RV, 1890-2004

The first panel shows the estimated conditional volatility and its long run component of GARCH-MIDAS model with quarterly rolling window RV and 4 MIDAS lag years of RV's in the MIDAS filter. They are all shown in standard deviation and annualized scale. The estimated parameters are shown in the second row of Table 2, In the second panel, these conditional variance and long run component are summed over quarters to show quarterly aggregated conditional variance and quarterly aggregated long run component with quarterly RV's for comparison. As in the first panel, these are shown in standard deviation and annualized scale.
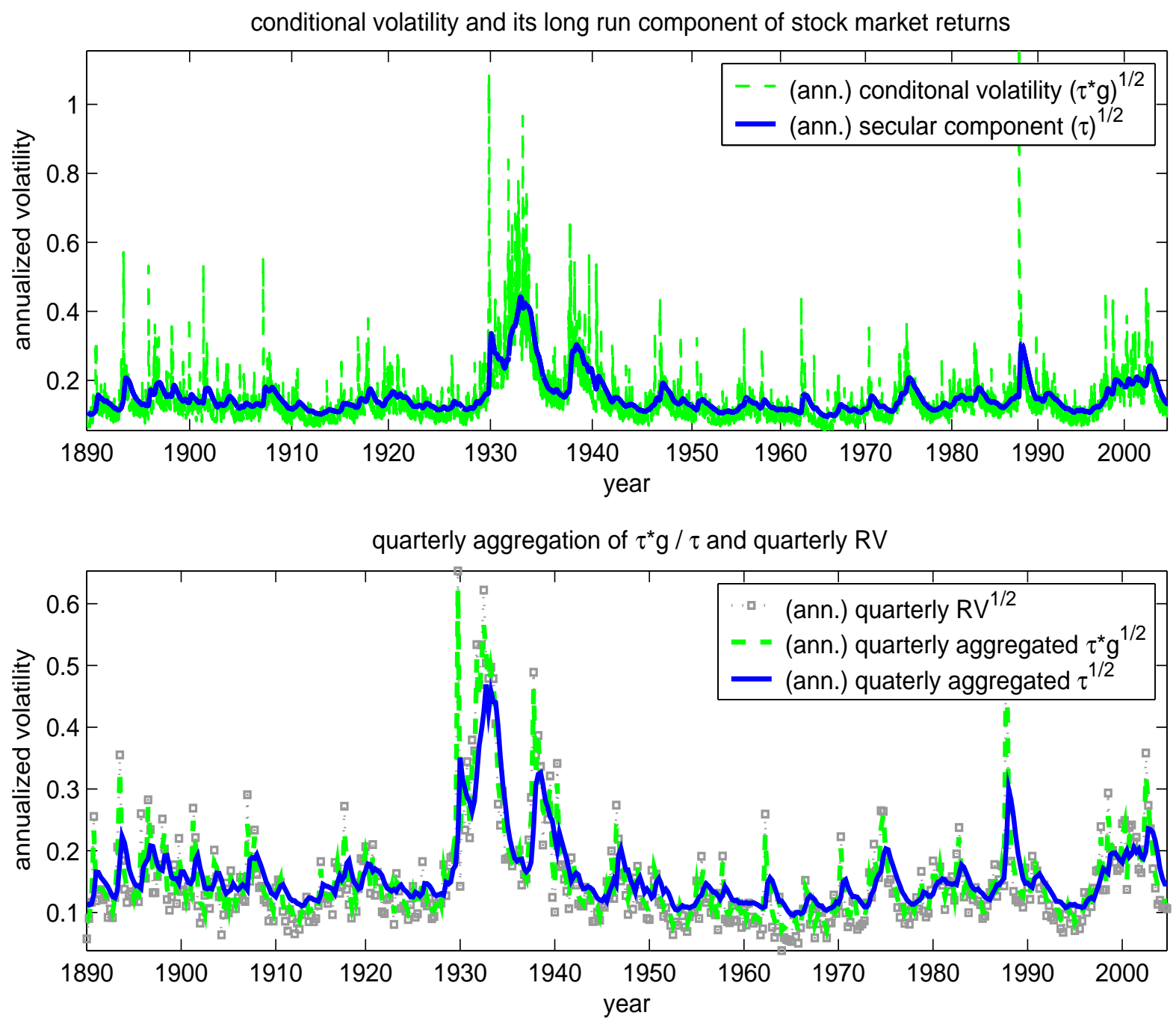


\section{Figure 4: Quarterly Macroeconomic Level Variables, 1886-2004}

These figures show macroeconomic level variables used in the GARCH-MIDAS with macroeconomic variables as specified in equation (12). PPI and IP represent producer price Index inflation rate and industrial production growth rate, respectively. The original dataset consists of monthly series of these variables. For PPI and IP, we obtained quarterly series by taking geometric means of 3 months, i.e. a quarter, of these series.
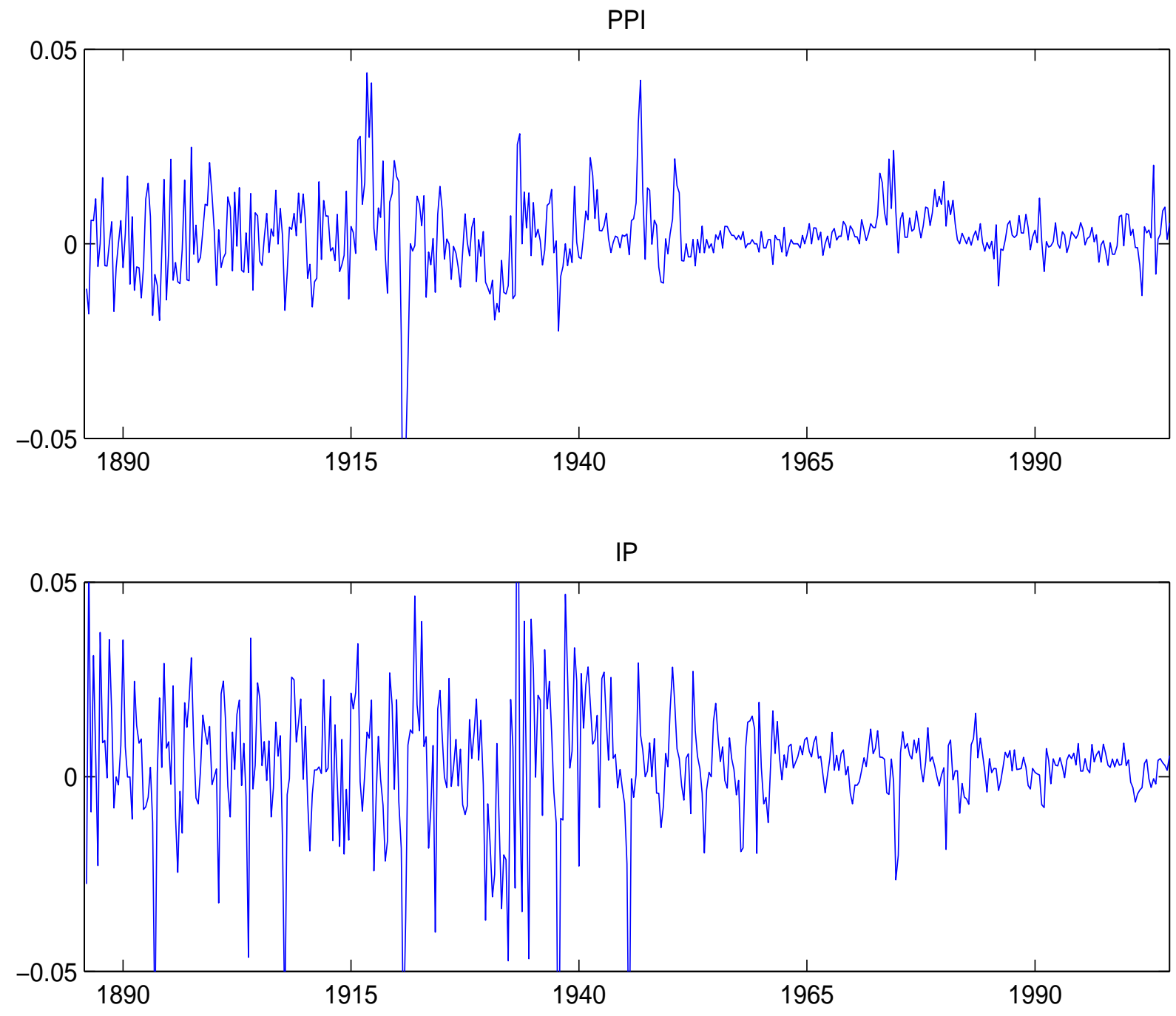


\section{Figure 5: Quarterly Macroeconomic Volatility, 1886-2004}

These figures show macroeconomic volatility variables used in the GARCH-MIDAS with macroeconomic variables as specified in equation (13). PPI and IP represent roducer price index inflation rate and industrial production growth rate, respectively. For these quarterly macroeconomic series, we adopt a variant of Schwert (1989) approach, as in equation (19), to measure macroeconomic volatility, which is shown in these figures. Note that the GARCH-MIDAS with macroeconomic variables as in equation (13) uses macroeconomic variance as an input and it is a squared term of volatility.

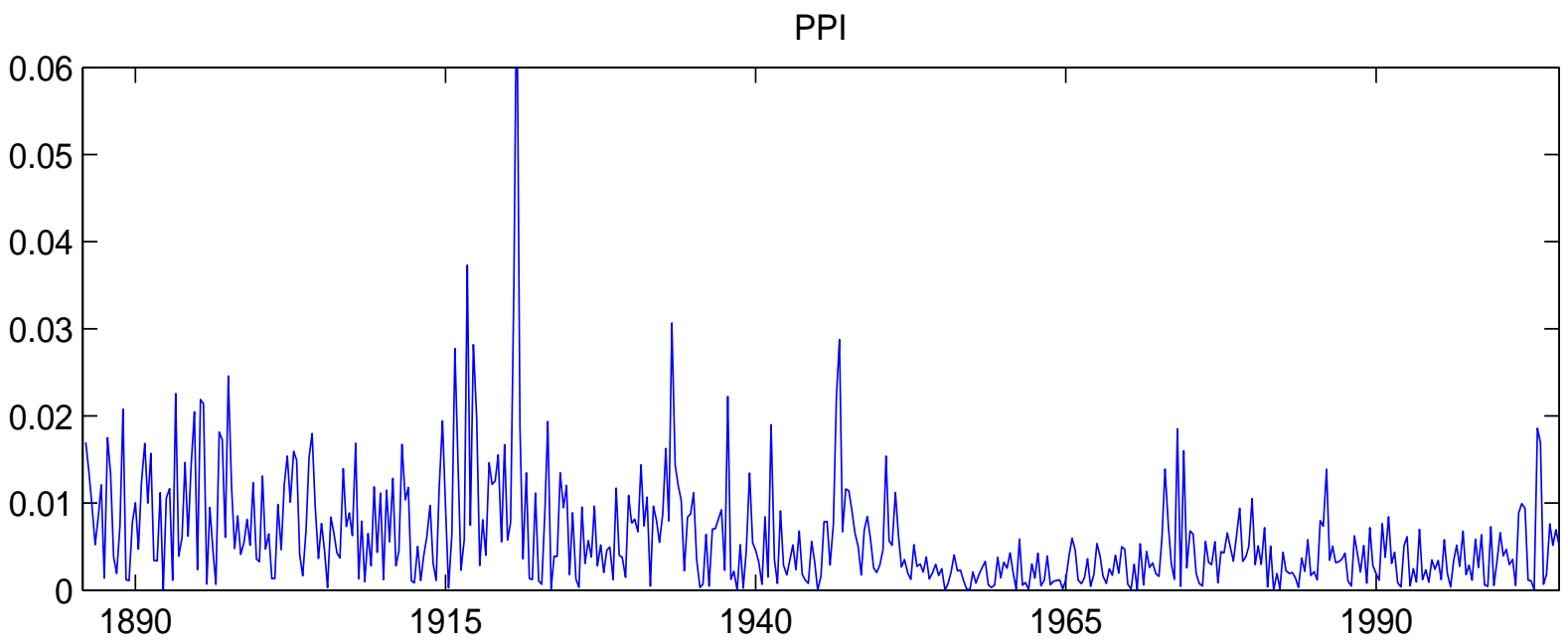

IP

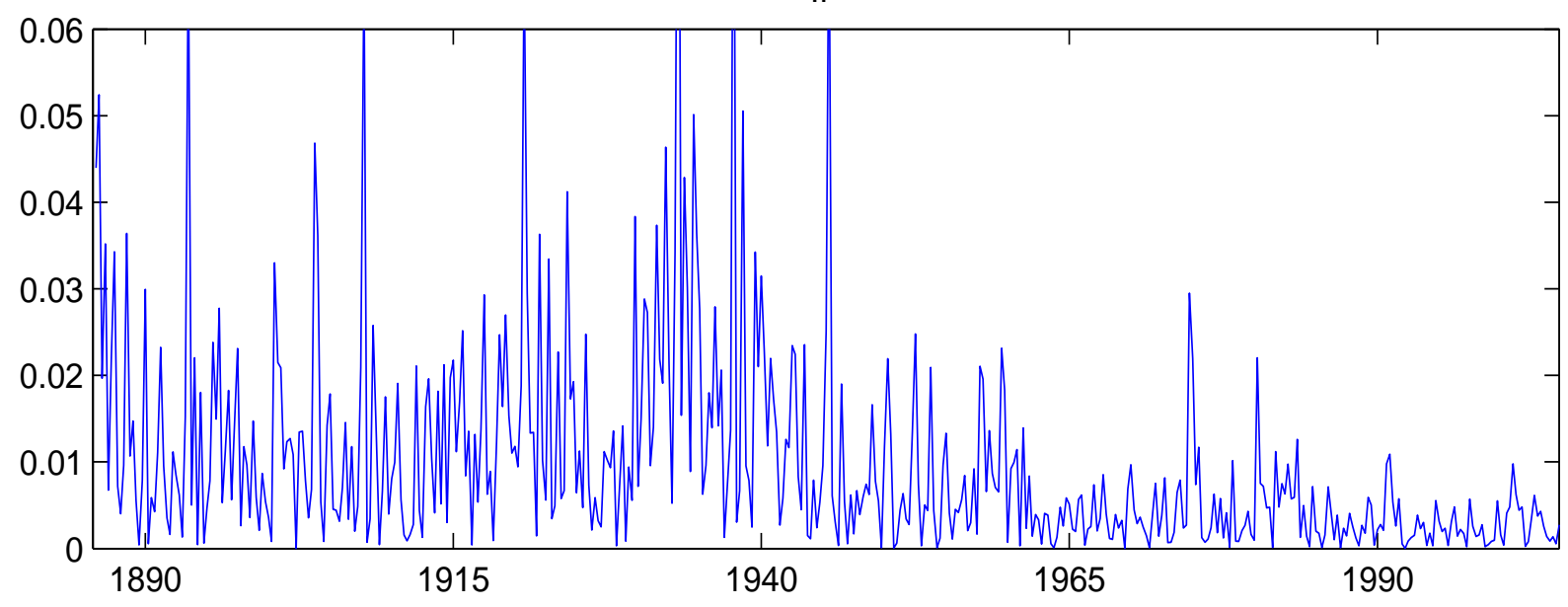


Figure 6: GARCH-MIDAS with Macroeconomic variables: Two-sided IP, 18902004

The figure pertains the two-sided IP level/volatility GARCH-MIDAS models for the full sample. 16 lags and 16 leads of both quarterly IP level and variance are filtered by MIDAS filter to model the long-run component $\tau$. The corresponding parameter estimates are shown in Table 7 The top panel contains the time series paths of $\tau$ and $g * \tau$. They are all shown in standard deviation and annualized scale. The lower panel contains the lag-lead weights for level and volatility of IP in the $\tau$ component according to equation (15).
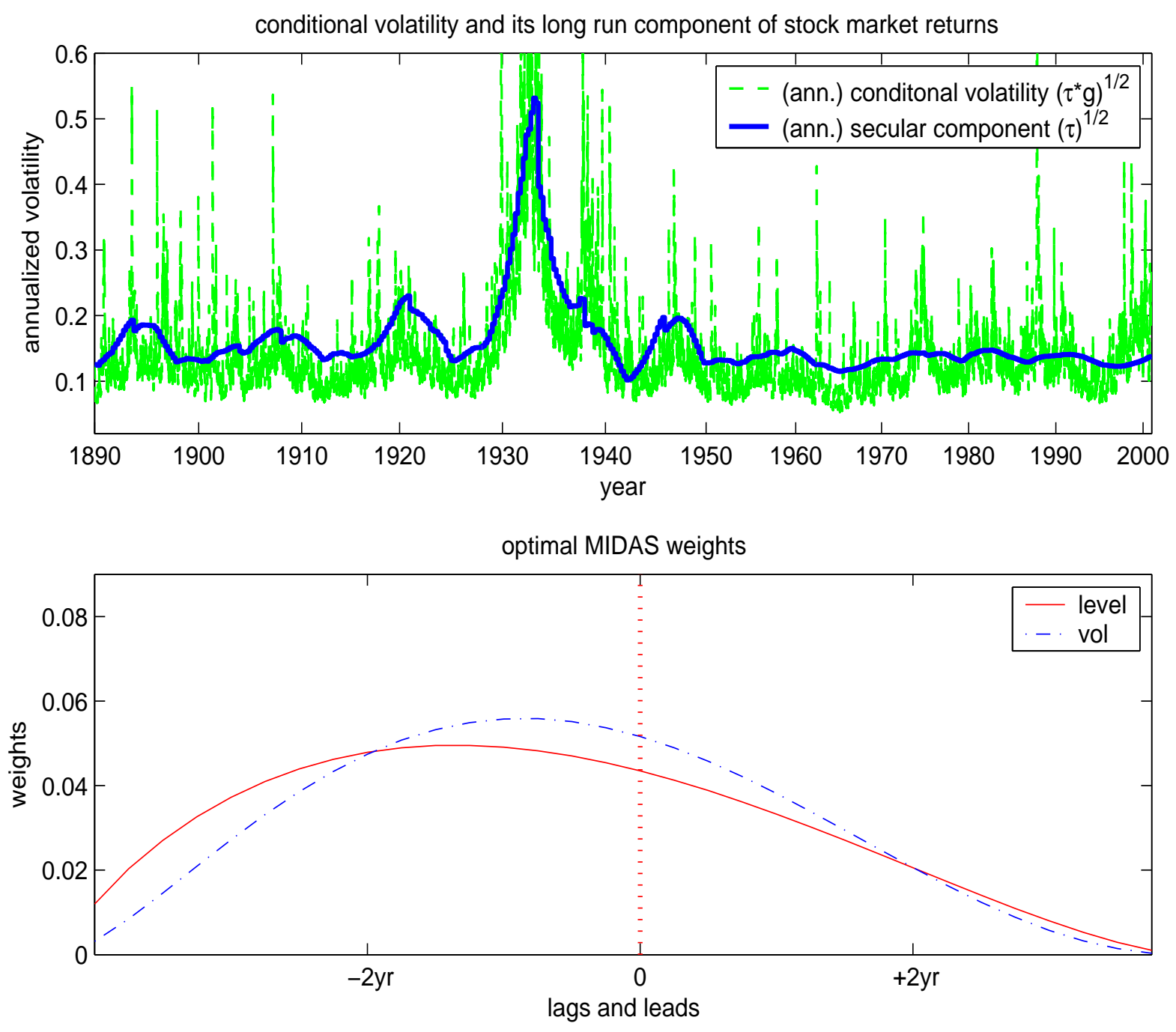
Figure 7: GARCH-MIDAS with Macroeconomic variables: Two-sided IP, 19201952

The figure pertains to the two-sided IP level/volatility GARCH-MIDAS models for the interwar subsample which includes the Great Depression period. 16 lags and 16 leads of both quarterly IP level and variance are filtered by MIDAS filter to model the long-run component $\tau$. The corresponding parameter estimates are shown in Table 7. The top panel contains the time series paths of $\tau$ and $g * \tau$. They are all shown in standard deviation and annualized scale. The lower panel contains the lag-lead weights for level and volatility of IP in the $\tau$ component according to equation (15).
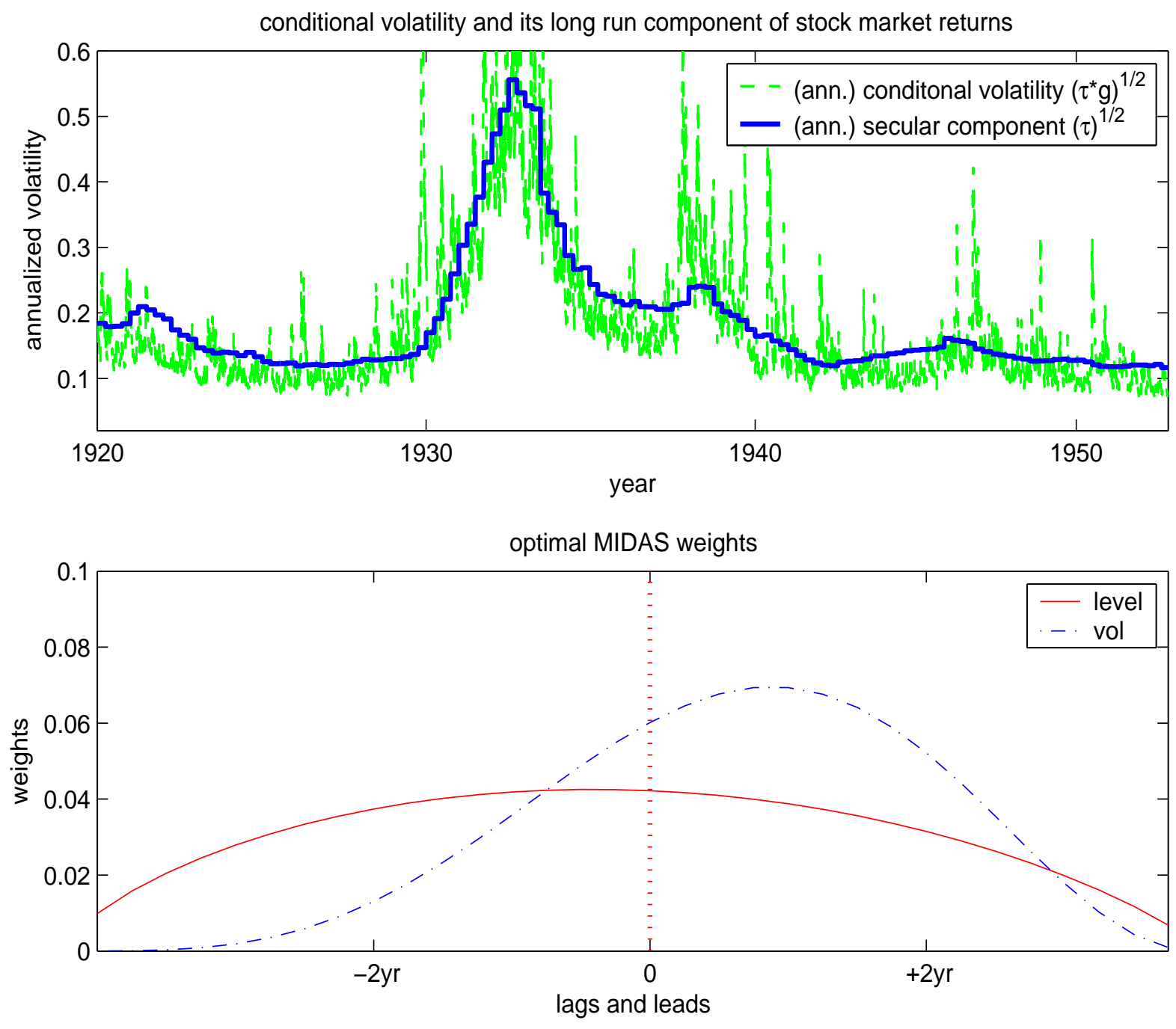
Figure 8: GARCH-MIDAS with Macroeconomic variables: Two-sided IP, 19852004

The figure pertains to the two-sided IP level/volatility GARCH-MIDAS models for the most recent subample which includes 1987 crash. 16 lags and 16 leads of both quarterly IP level and variance are filtered by MIDAS filter to model the long-run component $\tau$. The corresponding parameter estimates are shown in Table 7 The top panel contains the time series paths of $\tau$ and $g * \tau$. They are all shown in standard deviation and annualized scale. The lower panel contains the lag-lead weights for level and volatility of IP in the $\tau$ component according to equation (15).
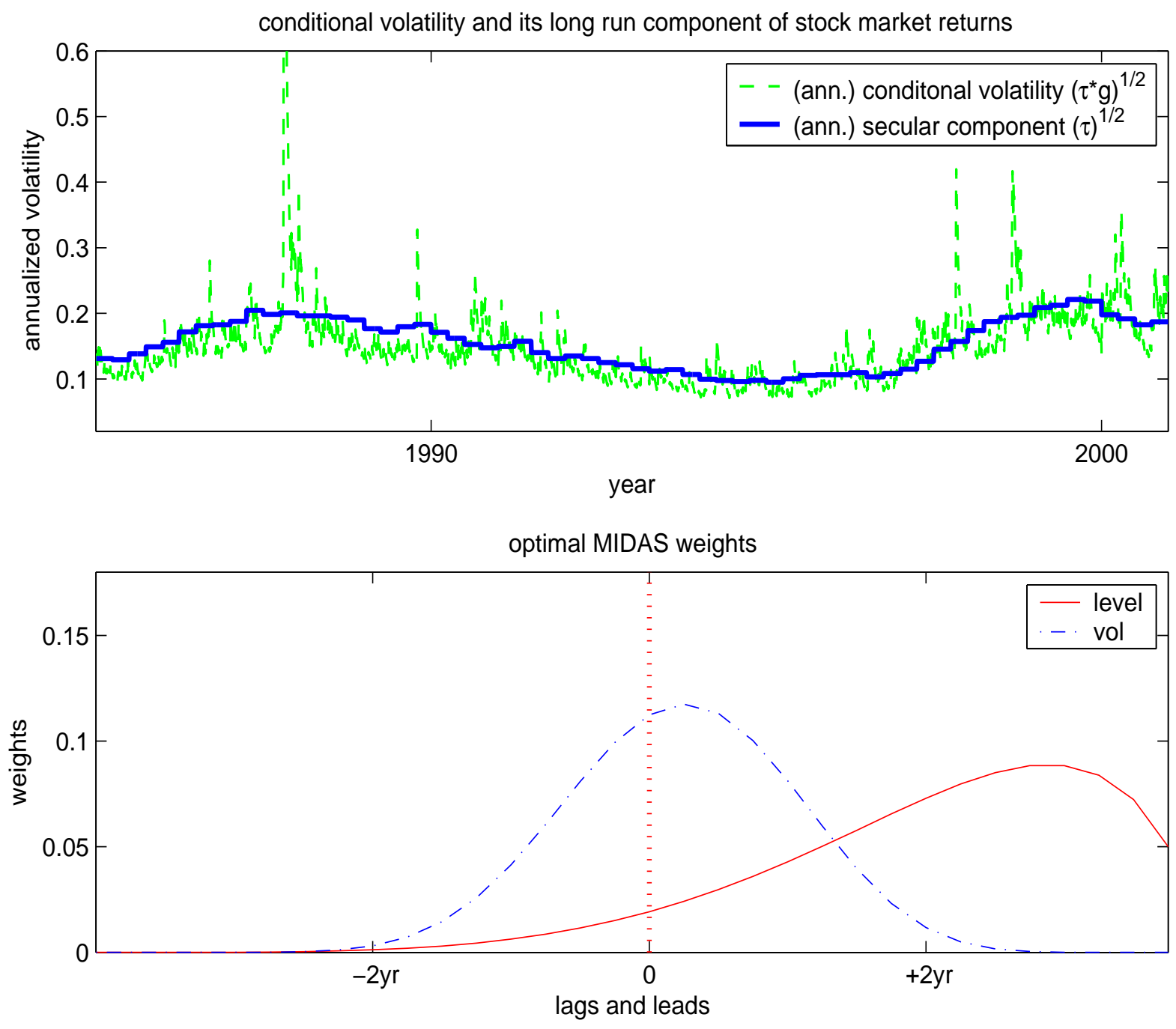
Figure 9: Comparison of $\tau$ component from Spline-GARCH model fitted over the Full Sample and the sub-samples

Long-run components as measured by $\tau$ in Spline-GARCH model fitted over the full sample and each of sub-samples are compared. The full sample period (1890-2004) is divided into three sub-sample periods: 1890-1919, 1920-1952, and 1953-2004. The optimal number of knots, with lowest BIC, for the full sample is seven while those of sub-samples are one, eight, and six, respectively. All are shown in standard deviation and annualized scale.

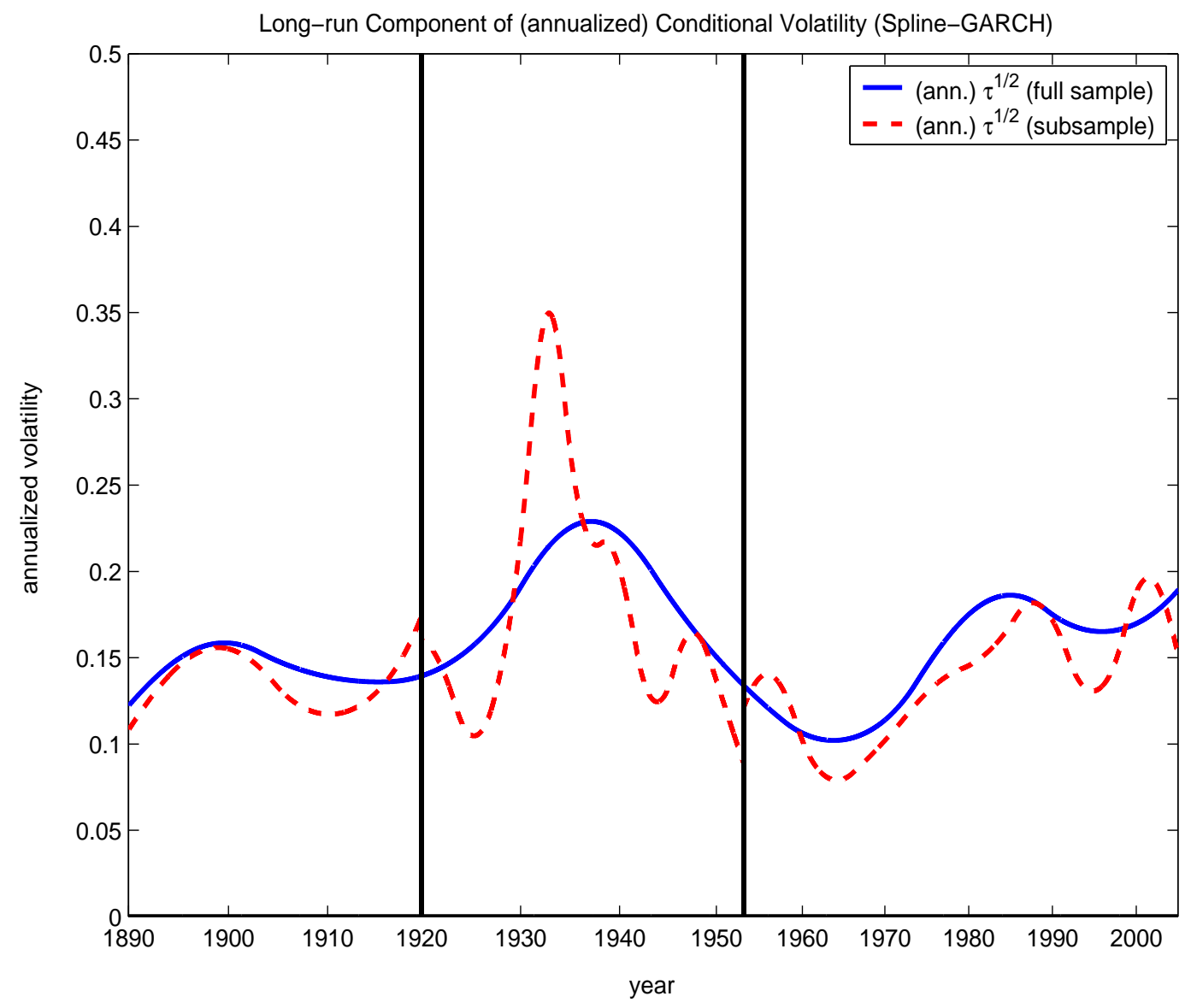

